Check for updates

Cite this: Phys. Chem. Chem. Phys., 2021, 23, 21554

\section{Local energy decomposition analysis and molecular properties of encapsulated methane in fullerene $\left(\mathrm{CH}_{4} \mathrm{aC}_{60}\right) \dagger$}

\author{
Aleksander Jaworski (D)* and Niklas Hedin (D)
}

\begin{abstract}
Methane has been successfully encapsulated within cages of $\mathrm{C}_{60}$ fullerene, which is an appropriate model system to study confinement effects. Its chemistry and physics are also relevant for theoretical model descriptions. Here we provide insights into intermolecular interactions and predicted spectroscopic responses of the $\mathrm{CH}_{4} \mathrm{QC}_{60}$ complex and compared them with results from other methods and with data from the literature. Local energy decomposition analysis (LED) within the domain-based local pair natural orbital coupled cluster singles, doubles, and perturbative triples (DLPNO-CCSD(T)) framework was used, and an efficient protocol for studies of endohedral complexes of fullerenes is proposed. This approach allowed us to assess energies in relation to electronic and geometric preparation, electrostatics, exchange, and London dispersion for the $\mathrm{CH}_{4} \mathrm{aC}_{60}$ endohedral complex. The calculated stabilization energy of $\mathrm{CH}_{4}$ inside the $\mathrm{C}_{60}$ fullerene was $-13.5 \mathrm{kcal} \mathrm{mol}^{-1}$ and its magnitude was significantly larger than the latent heat of evaporation of $\mathrm{CH}_{4}$. Evaluation of vibrational frequencies and polarizabilities of the $\mathrm{CH}_{4} \mathrm{OC}_{60}$ complex revealed that the infrared (IR) and Raman bands of the endohedral $\mathrm{CH}_{4}$ were essentially "silent" due to the dielectric screening effect of $\mathrm{C}_{60}$, which acted as a molecular Faraday cage. Absorption spectra in the UV-vis domain and ionization potentials of $\mathrm{C}_{60}$ and $\mathrm{CH}_{4}\left(\mathrm{aC}_{60}\right.$ were predicted. They were almost identical. The calculated ${ }^{1} \mathrm{H} /{ }^{13} \mathrm{C}$ NMR shifts and spin-spin coupling constants were in very good agreement with experimental data. In addition, reference DLPNO-CCSD(T) interaction energies for complexes with noble gases $\left(\mathrm{Ng}_{\mathrm{aC}} \mathrm{C}_{60}\right.$; $\mathrm{Ng}=\mathrm{He}, \mathrm{Ne}, \mathrm{Ar}, \mathrm{Kr}$ ) were calculated. The values were compared with those derived from supramolecular MP2/SCS-MP2 calculations and estimates with London-type formulas by Pyykkö and coworkers [Phys. Chem. Chem. Phys., 2010, 12, 6187-6203], and with values derived from DFT-based symmetry-adapted perturbation theory (DFT-SAPT) by Hesselmann \& Korona [Phys. Chem. Chem. Phys., 2011, 13, 732-743]. Selected points at the potential energy surface of the endohedral $\mathrm{He}_{2} \mathrm{aC}_{60}$ trimer were considered. In contrast to previous theoretical attempts with the DFT/MP2/SCS-MP2/DFT-SAPT methods, our calculations at the DLPNO-CCSD(T) level of theory predicted the $\mathrm{He}_{2} \mathrm{aC}_{60}$ trimer to be thermodynamically stable, which is in agreement with experimental observations.
\end{abstract}

Received 26th May 2021, Accepted 31st August 2021

DOI: 10.1039/d1cp02333k

rsc.li/pccp in trace amounts on Earth in carbon-rich rocks and soot. ${ }^{5,6}$ It has also been observed in micrometeorite impact residue on the

Carbon displays rich chemistry and physics with a variety of molecular allotropes, including common graphite and diamond, but also fullerenes, carbon nanotubes, and graphene. ${ }^{1-4}$ The most investigated fullerene is the $\mathrm{C}_{60}$ "Buckminsterfullerene" composed of 20 hexagons and 12 pentagons of $\mathrm{sp}^{2}$-hybridized carbon atoms fused into a pseudosphere with $\mathrm{a} \sim 7 \AA$ diameter, as displayed in Fig. 1. $\mathrm{C}_{60}$ occurs

Department of Materials and Environmental Chemistry, Stockholm University, SE-10691 Stockholm, Sweden. E-mail: aleksander.jaworski@mmk.su.se $\dagger$ Electronic supplementary information (ESI) available: Convergence tests, Cartesian coordinates of the models. See DOI: 10.1039/d1cp02333k
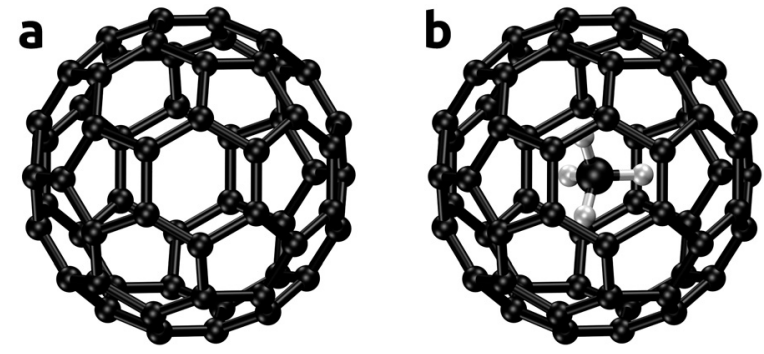

Fig. $1 \mathrm{C}_{60}$ fullerene (a) and its endohedral complex $\mathrm{CH}_{4} \mathrm{aC}_{60}$ (b). 
NASA Long Duration Exposure Facility orbiter, ${ }^{7}$ which indicates that it either survived impact at nominal encounter velocity of orbital debris $\left(\sim 11 \mathrm{~km} \mathrm{~s}^{-1}\right),{ }^{8}$ or was created in situ in space. Fullerenes isolated from meteorites revealed encapsulated atoms of noble gases with a ${ }^{3} \mathrm{He} /{ }^{4} \mathrm{He}$ isotope ratio of clearly extraterrestrial origin. ${ }^{9}$ Moreover, analyses of the 2019 data collected by the NASA/ESA Hubble Space Telescope confirmed spectral features of the ionized $\mathrm{C}_{60}^{+}$species in diffuse interstellar bands making it the largest molecule observed in space and indicating that fullerenes might play an important role in interstellar chemistry. ${ }^{10,11}$

The properties and chemistry of $\mathrm{C}_{60}$ have been studied; for example, the wave-particle duality was experimentally observed for $\mathrm{C}_{60} \cdot{ }^{12}$ Methods for preparation and separation have been established, ${ }^{13,14}$ and possibilities to encapsulate atoms and molecules inside the fullerene cage were recognized soon after its discovery. ${ }^{15} \mathrm{C}_{60}$ endohedral complexes with metal ions, noble gases, $\mathrm{H}_{2}, \mathrm{~N}_{2}$, and $\mathrm{H}_{2} \mathrm{O}$ have been prepared by high-energy collisions of ionized fullerene species, harsh conditions of high temperature and pressure, electric arc, or by organic synthesis methods called molecular surgery. ${ }^{16-19}$ The successful synthesis of an endohedral complex with $\mathrm{CH}_{4}$ was reported in 2019 by Whitby and coworkers. ${ }^{20}$ Methane is the largest, and the first organic molecule to be encapsulated in the $\mathrm{C}_{60}$ fullerene, and this complex denoted as $\mathrm{CH}_{4} @ \mathrm{C}_{60}$ is the main object of this study.

There is no obvious direct route to measure the stabilization energy in fullerene endohedral complexes and obtain insights into the interaction mechanisms. Experimental observations in this respect have been limited to assessing the efficiency/ probability of the given complex to be formed, and the main focus has been on spectroscopic and diffraction studies in relation to unusual physical properties of the encapsulated species. $^{21-23}$ Substantial theoretical efforts have been directed to studies of $\mathrm{C}_{60}$ endohedral complexes and associated intermolecular interactions. Pioneering $a b$ initio studies by Jerzy Cioslowski $^{24-26}$ at the Hartree-Fock (HF) level of theory were expanded by studies of Bühl et al., ${ }^{27,28}$ Patchkovskii et al., ${ }^{29}$ Darzynkiewicz et al., ${ }^{30}$ and Autschbach et al. ${ }^{31}$ among others, ${ }^{32-37}$ where density functional theory (DFT) and second-order Møller-Plesset perturbation theory (MP2) were used. However, within the supramolecular approach with the interaction energy being the arithmetic relation of related energies $\left(E_{\mathrm{int}}=E_{\mathrm{AB}}-\left(E_{\mathrm{A}}+E_{\mathrm{B}}\right)\right)$, DFT is essentially blind to long-range dispersion. This limitation has typically been addressed by using empirical correction schemes for the dispersion contributions. ${ }^{38-42}$ MP2 is the lowest $a b$ initio method that accounts for "real" dispersion effects but it is unbalanced and its performances for weak, noncovalent interactions are modest and system dependent. ${ }^{43}$ Symmetry-adapted perturbation theory (SAPT) with monomer description at the DFT level (DFT-SAPT) developed by Krzysztof Szalewicz and coworkers is an alternative approach to account for dispersion contributions. $^{44-46}$ Within SAPT, the interaction energy is obtained as a sum of physical contributions, free from basis set superposition error (BSSE). ${ }^{47}$ Hence, the most reliable stabilization energies for $\mathrm{C}_{60}$ endohedral complexes so far have been obtained with DFT-SAPT by Hesselmann and Korona. ${ }^{48,49}$ In parallel developments, approximate London-type formulas have been derived by Pyykkö and coworkers for the estimation of dispersion interaction in endohedral systems. ${ }^{50,51}$

Attractive dispersion interactions between nonpolar species such as $\mathrm{C}_{60}$ and $\mathrm{CH}_{4}$ (or noble gases) are purely quantum mechanical and originate from instantaneous effects of dynamical electron correlation. ${ }^{52}$ For systems of chemical interest that can be correctly described by a single reference wave function, the most robust (and still tractable) way of introducing electron correlation is the coupled cluster singles, doubles, and perturbative triples $\operatorname{CCSD}(\mathrm{T})$ method. ${ }^{53}$ It is the "gold standard" of quantum chemistry. However, a canonical implementation of the $\operatorname{CCSD}(\mathrm{T})$ model exhibits a seventh-order scaling with the system size, which results in tremendous computational expenses when considering systems larger than 15-25 atoms. Frank Neese and coworkers have recently developed an efficient implementation of the domain-based local pair natural orbital coupled cluster method (DLPNO-CCSD(T)). ${ }^{54-56}$ Briefly, in the DLPNO-CCSD(T) approach the correlation energy is expressed as a sum of electron pair correlation energies, which enables the distinction between the "weak pairs" with negligible contributions to the total correlation energy and the "strong pairs" that constitute the dominant, desired part. In this way, the "weak pairs" can be treated with a computationally more efficient second-order perturbation theory, whereas only the essential "strong pairs" are subjected to an accurate coupled cluster treatment, which greatly reduces the computational complexity. With appropriately selected pair-selection thresholds, this model is capable of recovering $99.9 \%$ of the correlation energy of its canonical counterpart. It reproduces the $\operatorname{CCSD}(\mathrm{T})$ results within a chemical accuracy at substantially reduced computational efforts. ${ }^{57,58}$ This approach extends the possibility of obtaining accurate $a b$ initio energies to systems for which only DFT has been applicable so far. ${ }^{59,60}$ Moreover, using a local energy decomposition (LED) protocol allows for a physical meaningful decomposition of the interaction energy within the DLPNO-CCSD(T) framework. ${ }^{52,61,62}$

In this study, the goal was to provide an accurate interaction energy decomposition for the $\mathrm{CH}_{4} @ \mathrm{C}_{60}$ complex and the encapsulation energy barrier using the DLPNO-CCSD(T) method. This approach is not biased by the parametrization inherent to the DFT models, including the type of exchangecorrelation approximation and dispersion correction scheme. The reference interaction energies for endohedral complexes with noble gases were provided and compared with results by Pyykkö et al. and Hesselmann and Korona. ${ }^{49-51}$

\section{Methods}

The counterpoise-corrected interaction energy of molecular fragments $X$ and $Y$ can be expressed as: ${ }^{61}$

$$
\begin{aligned}
\Delta E= & {\left[E_{X Y}^{X Y}(X Y)-\left(E_{X}^{X Y}(X Y)+E_{Y}^{X Y}(X Y)\right)\right] } \\
& +\left[\left(E_{X}^{X Y}(X)-E_{X}^{X}(X)\right)+\left(E_{Y}^{X Y}(Y)-E_{Y}^{Y}(Y)\right)\right] \\
\equiv & \Delta E_{\text {int }}+\Delta E_{\text {geo-prep }}
\end{aligned}
$$


where the $E_{A}^{B}(C)$ notation denotes the energy of fragment $A$ calculated at the energy-optimized coordinates of $B$ and using a basis set of system $C$. The $\Delta E_{\text {int }}$ term is the "electronic interaction", whereas $\Delta E_{\text {geo-prep }}$ is the geometric preparation contribution that accounts for the differences between equilibrium molecular geometries of isolated fragments and those in a complex ("deformation energy").

The electronic interaction energy $\Delta E_{\text {int }}$ is decomposed within the following DLPNO-CCSD(T)-LED decomposition scheme:

$$
\begin{aligned}
\Delta E_{\mathrm{int}}= & \Delta E_{\mathrm{int}}^{\mathrm{HF}}+\Delta E_{\mathrm{int}}^{\mathrm{C}} \\
= & \Delta E_{\mathrm{int}}^{\mathrm{HF}}+\Delta E_{\mathrm{int}}^{\mathrm{C}-\mathrm{CCSD}}+\Delta E_{\mathrm{int}}^{\mathrm{C}-(\mathrm{T})} \\
= & \Delta E_{\mathrm{el}-\mathrm{prep}}^{\mathrm{HF}}+E_{\text {elstat }}+E_{\text {exch }} \\
& +\Delta E_{\text {non-disp }}^{\mathrm{C}}+\Delta E_{\text {disp }}^{\mathrm{C}}+\Delta E_{\mathrm{int}}^{\mathrm{C}-(\mathrm{T})}
\end{aligned}
$$

The interaction energy $\Delta E_{\text {int }}$ is decomposed into that from the Hartree-Fock level of theory $\Delta E_{\mathrm{int}}^{\mathrm{HF}}$ and the corrections due to inclusion of electron correlation $\Delta E_{\mathrm{int}}^{\mathrm{C}}$. The latter is decomposed further into the interaction energy contribution at the CCSD level of theory $\Delta E_{\mathrm{int}}^{\mathrm{C}-\mathrm{CCSD}}$ and that resulting from the perturbative triple excitations $\Delta E_{\mathrm{int}}^{\mathrm{C}-(\mathrm{T})}$. The Hartree-Fock interaction energy $\Delta E_{\mathrm{int}}^{\mathrm{HF}}$ is decomposed into the electronic preparation contribution $\Delta E_{\mathrm{el}-\mathrm{HF}}^{\mathrm{HF}}$, which corresponds to the energy needed to bring the electronic structures of the isolated fragments into the one optimal for the interaction ("energy investment") and into attractive electrostatic $E_{\text {elstat }}$ and exchange $E_{\text {exch }}$ contributions. The CCSD correlation interaction energy is partitioned further into the genuine London dispersion interaction energy $E_{\mathrm{disp}}^{\mathrm{C}}$ and the non-dispersive correlation contribution $E_{\text {non-disp. }}^{\mathrm{C}}$ The latter provides (dynamical) corrections to the Hartree-Fock polarization effects, "dynamic charge polarization". We refer the reader to the original articles for a detailed description of the method and implementation. ${ }^{52,61,62}$

\section{Computational details}

All calculations were performed with the ORCA code $\mathrm{e}^{63,64}$ using a very tight convergence tolerance of $1 \times 10^{-9} E_{\mathrm{h}}$. The evaluation of Coulomb and exchange integrals was accelerated with the RIJCOSX approximation ${ }^{65}$ with the def $2 / \mathrm{J}$ Coulomb-fitting basis set ${ }^{66}$ and tightened grid (GridX5; a further increase was verified to have a negligible effect). Geometry optimizations were converged to very tight thresholds (VeryTightOpt setting) using the revised PBE "revPBE" exchange-correlation DFT approximation $^{67,68}$ together with atom-pairwise dispersion correction based on tight binding partial charges (D4). ${ }^{42}$ The polarization-consistent segmented pcseg- 1 basis set, ${ }^{69}$ and the increased DFT integration grid (Grid5 NoFinalGrid) were used. The choice of the revPBE model was based on its performance in a recent and thorough benchmark study (best among the computationally efficient gradient-corrected GGA functionals). ${ }^{70}$ To confirm the global energy minima at the potential energy surfaces, and to evaluate vibrational IR and
Raman spectra, Hessians, and dipole polarizabilities were calculated. The transition state search involved many consecutive computations of the Hessians towards the first-order saddle point. Thereby computational efforts were reduced by using the smaller pcseg-0 basis set for atoms of aryl groups for the open-cage models. Cartesian coordinates of the models are provided in the ESI. $\dagger$ DLPNO-CCSD(T) calculations were performed with a Foster-Boys localization scheme, a full MP2 guess, and $\mathrm{T}_{0}$ perturbative triples correction based on semicanonical approximation (the difference with respect to the iterative $T_{1}$ algorithm was verified to be small; see the ESI $\dagger$ ). ${ }^{71}$ Correlation-consistent cc-pVXZ (X = D, T, Q, 5) orbital basis sets ${ }^{72-74}$ were employed together with the corresponding cc-pVXZ/C auxiliary basis sets. ${ }^{75}$ The chosen PNO truncation thresholds are discussed in the results and discussion section. Computations were performed on a cluster node equipped with two Intel Xeon ${ }^{\circledR}$ Gold $^{\circledR} 6126$ CPUs (2.6 GHz; 12-core) and $256 \mathrm{~GB}$ of RAM.

\section{Results and discussion}

\section{The choice of PNO truncation thresholds and basis sets}

To facilitate accuracy control in a user-friendly manner, the authors of the DLPNO-CCSD(T) method have implemented three levels of predefined PNO truncation thresholds. These levels converge towards the method limit at increasing computational cost: LoosePNO, NormalPNO, and TightPNO. ${ }^{57}$ The first two offer sufficient accuracy for most applications $\left(<0.5 \mathrm{kcal} \mathrm{mol}^{-1}\right.$ deviation for the evaluations of total energy with respect to the $\operatorname{CCSD}(\mathrm{T})$ reference),${ }^{57}$ but for analysis of weak intermolecular interactions, the TightPNO setting should be used. This ensures that the electron pairs that dominate the interaction are being treated at the coupled cluster level. ${ }^{61}$ However, fullerenes are challenging for local coupled cluster methods. The large number of (long-range) $\pi-\pi$ interactions in the highly delocalized $\pi$-system of fullerenes render calculations with the TightPNO setting and accurate basis sets very demanding. ${ }^{58,76,77}$ The DLPNO-CCSD(T) in its current implementation is formally a linear-scaling method when considering the iterative part, but the RI-PNO integral transformations on large systems add substantial prefactors to the total computation times, which in turn limit the feasibility, also due to the memory and disk space requirements. Therefore, based on test calculations for the $\mathrm{CH}_{4} \cdots \mathrm{C}_{6} \mathrm{H}_{6}$ dimer (Fig. 2), which is expected to exhibit a similar nature of noncovalent interactions to those in the $\mathrm{CH}_{4} @ \mathrm{C}_{60}$ complex, we used a multilevel approach as proposed by Sparta et al. ${ }^{59}$ Within the multilevel DLPNO approach the test $\mathrm{CH}_{4} \cdots \mathrm{C}_{6} \mathrm{H}_{6}$ system was divided into $\mathrm{CH}_{4}$ and $\mathrm{C}_{6} \mathrm{H}_{6}$ fragments. By this division, the intrafragment electron pairs with their orbitals entirely localized on one molecular fragment could be separated from those that gave rise to intermolecular interactions. ${ }^{59}$ In Table 1 , dispersion interaction and time used for the DLPNO-CCSD(T)-LED calculations for the $\mathrm{CH}_{4} \cdots \mathrm{C}_{6} \mathrm{H}_{6}$ dimer are presented (total interaction energies as well as the $\Delta E_{\text {non-disp }}$ and $\Delta E_{\text {int }}^{\mathrm{C} \text { (T) }}$ terms are included in the ESI $\dagger$ ). We monitored the convergence of the 

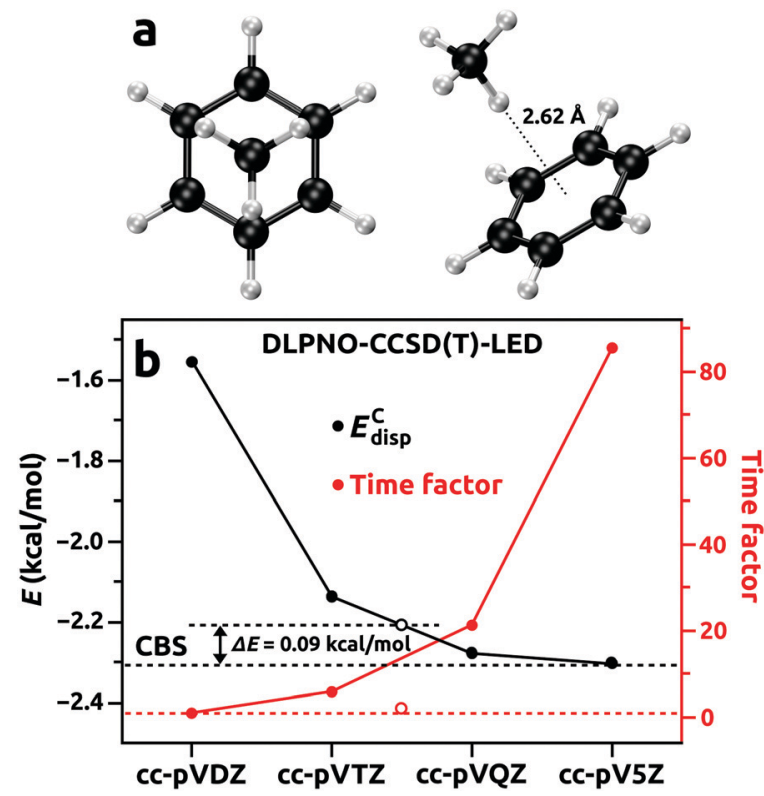

Fig. 2 (a) Molecular geometry of the $\mathrm{CH}_{4} \cdots \mathrm{C}_{6} \mathrm{H}_{6}$ dimer optimized at the revPBE-D4/pcseg-1 level of theory. (b) Basis set convergence for the DLPNO-CCSD(T)-LED dispersion interaction energy component $E_{\text {disp }}^{C}$ using TightPNO settings. Open circles correspond to the calculation with the multilevel scheme proposed in the last row of Table 1.

energy component for the dispersion interaction $\left(E_{\text {disp }}^{\mathrm{C}}\right)$ since it depends solely on the treatment of the electron correlation, and therefore is critically sensitive to the truncation thresholds of the PNO and the (in)completeness of the basis set. By using a TightPNO setting for both intrafragment and interfragment pairs, smooth convergence towards the limit of a complete basis set (CBS) was observed (see Fig. 2). The dispersion interaction energy essentially converged at the TightPNO/ cc-pVQZ level. Unfortunately, this setup would involve prohibitive computational costs when applied to endohedral fullerene complexes. Therefore, for routine applications, we propose a more

Table 1 Dispersion contribution $\left(E_{\text {disp }}^{C} ; \mathrm{kcal} \mathrm{mol}^{-1}\right)$ to the interaction energy in the $\mathrm{CH}_{4} \cdots \mathrm{C}_{6} \mathrm{H}_{6}$ dimer calculated within the DLPNO-CCSD(T)LED scheme using different PNO truncation settings ${ }^{a}$ and basis sets, as well as extrapolated to the complete basis set limit $(C B S)^{b}$

\begin{tabular}{|c|c|c|c|c|c|c|}
\hline $\begin{array}{l}\text { Inter } \\
\mathrm{CH}_{4} \cdots \mathrm{C}_{6} \mathrm{H}_{6}\end{array}$ & Intra $\mathrm{CH}_{4}$ & $\begin{array}{l}\text { Intra } \\
\mathrm{C}_{6} \mathrm{H}_{6}\end{array}$ & $\begin{array}{l}\text { Basis } \\
\text { set } \mathrm{CH}_{4}\end{array}$ & $\begin{array}{l}\text { Basis } \\
\text { set } \mathrm{C}_{6} \mathrm{H}_{6}\end{array}$ & $E_{\text {disp }}^{\mathrm{C}}$ & $\begin{array}{l}\text { Time } \\
\text { factor }^{c}\end{array}$ \\
\hline & & & & & -2.31 & $\times 112$ \\
\hline NO & Tig & & V5Z & cc-pV & -2.30 & $\times 85$ \\
\hline TightPNO & TightPNO & TightPNO & cc-pVQZ & cc-pVQZ & -2.28 & $\times 21$ \\
\hline TightPNO & TightPNO & TightPNO & cc-pVTZ & cc-pVTZ & -2.14 & $\times 6$ \\
\hline TightPNO & TightPNO & TightPNO & cc-pVDZ & cc-pVDZ & -1.55 & $\times 1$ \\
\hline TightPNO & NormalPNO & LoosePNO & cc-pVQZ & cc-pVTZ & -2.22 & $\times 2$ \\
\hline
\end{tabular}

${ }^{a}$ TightPNO: $T_{\text {CutPairs }}=10^{-5}, T_{\text {CutDO }}=5 \times 10^{-3}, T_{\text {CutPNO }}=1.00 \times 10^{-6}$, $T_{\text {CutMKN }}=10^{-3}$; NormalPNO: $T_{\text {CutPairs }}=10^{-4}, T_{\text {CutDO }}=1 \times 10^{-2}, T_{\text {CutPNO }}=$ $3.33 \times 10^{-7}, T_{\text {CutMKN }}=10^{-3}$; LoosePNO: $T_{\text {CutPairs }}=10^{-3}, T_{\text {CutDO }}=2 \times$ $10^{-2}, T_{\text {CutPNO }}=1.00 \times 10^{-7}, T_{\text {CutMKN }}=10^{-3}$; see ref. $57 .{ }^{b}$ Estimated from cc-pVXZ $(\mathrm{X}=\mathrm{T}, \mathrm{Q}, 5)$ results using an extrapolation scheme by Helgaker et al..$^{78,79 c}$ Time estimates based on computations using 8 cores of the Intel ${ }^{\circledR}$ Xeon ${ }^{\circledR}$ Gold $6126 \mathrm{CPU}$ and $256 \mathrm{~GB}$ of RAM. Calculations were run in competition with other processes on the cluster, so there might be fluctuations in the computation time estimates. tractable multilevel DLPNO scheme. In this scheme, the truncation thresholds for the intrafragment PNO for the guest (in this case $\left.\mathrm{CH}_{4}\right)$ and for a troublesome delocalized $\pi$-system $\left(\mathrm{C}_{6} \mathrm{H}_{6}, \mathrm{C}_{60}\right)$ are reduced to the NormalPNO and LoosePNO, respectively, whereas the critical interfragment pairs are subjected to an accurate TightPNO evaluation. Together with the combination of the cc-pVQZ/cc-pVTZ basis sets, the multilevel scheme proposed in the last row in Table 1 offers massive computational savings without compromising accuracy to any significant extent. For a test conducted for the $\mathrm{CH}_{4} \cdots \mathrm{C}_{6} \mathrm{H}_{6}$ dimer, this approach recovered $>95 \%$ of the dispersion interaction energy when compared to the TightPNO/CBS reference, while being only twice as expensive as the TightPNO/cc-pVDZ calculation. The contribution from weak pairs to the $E_{\text {disp }}^{\mathrm{C}}$ was less than $4 \%$ throughout the calculations presented in Table 1. Moreover, the related interaction energies compared well with previously reported accurate $a b$ initio calculated energies for the $\mathrm{CH}_{4} \cdots \mathrm{C}_{6} \mathrm{H}_{6}$ dimer. When using the proposed multilevel DLPNO-CCSD $(\mathrm{T})$ setup, a total interaction energy $\Delta E_{\text {int }}=$ $-1.34 \mathrm{kcal} \mathrm{mol}^{-1}$ was calculated, which agreed very well with the $\operatorname{CCSD}(\mathrm{T}) /$ aug-cc-pVTZ result of $-1.39 \mathrm{kcal} \mathrm{mol}^{-1}$ by Ringer et al. ${ }^{80}$ The estimated dispersion contribution of $-2.03 \mathrm{kcal} \mathrm{mol}^{-1}$ at the SAPT2/aug-cc-pVDZ level of theory by Ringer et al. ${ }^{80}$ was close to our value of $-2.22 \mathrm{kcal} \mathrm{mol}^{-1}$. The above indicates that the multilevel DLPNO-CCSD(T) setup tailored for substantially more demanding calculations on endohedral complexes of fullerenes is robust.

\section{DLPNO-CCSD(T)-LED analysis of the $\mathrm{CH}_{4} @ \mathrm{C}_{60}$}

In Table 2 the corresponding bond lengths of energy-optimized geometries of the $\mathrm{CH}_{4}, \mathrm{C}_{60}$, and $\mathrm{CH}_{4} @ \mathrm{C}_{60}$ endohedral complex are shown. As a consequence of $I_{\mathrm{h}}$ symmetry, the $\mathrm{C}_{60}$ fullerene molecular structure is defined by the two distinct $\mathrm{C}-\mathrm{C}$ distances $r_{1}$ and $r_{2}$ that originate from the bonds between fused pentagons and hexagons $\left(r_{1}\right)$ and the shorter ones between two hexagons $\left(r_{2}\right)$. The energy-optimized model of $\mathrm{C}_{60}$ exhibited excellent agreement with experimental bond length estimates. For $r_{1}$ the deviation was $<0.005 \AA$, and $r_{2}$ coincided with the empirical $\mathrm{C}-\mathrm{C}$ distance. This indicated that the revPBE-D4/ pcseg-1 level of theory was capable of delivering robust models of fullerene systems.

For comparison, reported geometries of $\mathrm{C}_{60}$ optimized at the (ab initio) HF and MP2 levels of theory have revealed considerable deviations of $\mathrm{C}-\mathrm{C}$ bond lengths, ${ }^{35,36}$ whereas previous tests of different DFT approximations have not included dispersion corrections. $^{35,36}$ Of note, at the revPBE-D4/pcseg-1 level of theory the geometries of both $\mathrm{CH}_{4}$ and $\mathrm{C}_{60}$ remained essentially

Table 2 Bond lengths $(r ; \AA)$ for the molecular geometries of $\mathrm{CH}_{4}, \mathrm{C}_{60}$, and $\mathrm{CH}_{4} @ \mathrm{C}_{60}$ endohedral complex optimized at the revPBE-D4/pcseg-1 level of theory and used for the DLPNO-CCSD(T) calculations. Experimental values are given in parentheses ${ }^{a}$

\begin{tabular}{llll}
\hline & $\mathrm{CH}_{4}$ & $\mathrm{C}_{60}$ & $\mathrm{CH}_{4} @ \mathrm{C}_{60}$ \\
\hline$r_{(\mathrm{H}-\mathrm{C})}$ & $1.095(1.086)$ & & 1.095 \\
$r_{1(\mathrm{C}-\mathrm{C})}$ & & $1.454(1.458)$ & 1.454 \\
$r_{2(\mathrm{C}-\mathrm{C})}$ & & $1.401(1.401)$ & 1.401 \\
${ }^{a}$ From ref. 81 and 82. & &
\end{tabular}


unchanged upon formation of the $\mathrm{CH}_{4} @ \mathrm{C}_{60}$ endohedral complex. We note however that in our DFT optimized model of $\mathrm{CH}_{4}$ the $\mathrm{C}-\mathrm{H}$ bond length was overestimated by $\sim 0.01 \AA$, and did not correspond to an energy minimum at the coupled cluster level of theory, for which the equilibrium $\mathrm{C}-\mathrm{H}$ distance was shorter and closer to the experimental estimate. The encapsulation of $\mathrm{CH}_{4}$ in $\mathrm{C}_{60}$ is associated with a tiny shortening $(<0.001 \AA)$ of the $\mathrm{C}-\mathrm{H}$ bond lengths. Therefore, the total DLPNO-CCSD(T) energy of the $\mathrm{CH}_{4}$ molecule calculated at molecular geometry corresponding to that in the $\mathrm{CH}_{4} @ \mathrm{C}_{60}$ complex was lower compared to that for the isolated $\mathrm{CH}_{4}$. Although this effect was very small and had no implications on the evaluation of the electronic interaction energy $\Delta E_{\text {int }}$ in the $\mathrm{CH}_{4} @ \mathrm{C}_{60}$ complex, it would lead to an unphysical lowering of the "deformation energy", the $\Delta E_{\text {geo-prep }}$ term in eqn (1). Therefore, to provide the most realistic values the evaluation of $\Delta E_{\text {geo-prep }}$ included only the contribution from the deformation of the $\mathrm{C}_{60}$ cage.

In Fig. 3, interaction energy contributions are presented from the DLPNO-CCSD(T)-LED analysis of the $\mathrm{CH}_{4} @ \mathrm{C}_{60}$ endohedral complex. The total interaction energy for the complex is represented as a sum of seven physical contributions: $\Delta E_{\mathrm{el}-\mathrm{HF}}^{\mathrm{HF}}$, $E_{\text {elstat }}, E_{\text {exch }}, \Delta E_{\text {non-disp }}^{\mathrm{C}}, E_{\text {disp }}^{\mathrm{C}}, \Delta E_{\text {int }}^{\mathrm{C} \text { (T) }}$, and $\Delta E_{\text {geo-prep }}$ (according to eqn (1) and (2)). The large and positive electronic preparation term $\Delta E_{\text {el-prep }}^{\mathrm{HF}}=+81.22 \mathrm{kcal} \mathrm{mol}^{-1}$ is counteracted by attractive contributions due to electrostatics and exchange $\left(E_{\text {elstat }}=\right.$ $-39.73 \mathrm{kcal} \mathrm{mol}^{-1}, E_{\text {exch }}=-21.00 \mathrm{kcal} \mathrm{mol}^{-1}$ ). However, the summed components of the interaction energy at the HartreeFock level $\left(\Delta E_{\text {el-prep }}^{\mathrm{HF}}+E_{\text {elstat }}+E_{\text {exch }}\right)$ resulted in substantially repulsive interaction of $\Delta E_{\mathrm{int}}^{\mathrm{HF}}=+20.49 \mathrm{kcal} \mathrm{mol}^{-1}$. This value was basically identical to the value calculated by Pyykkö and coworkers at the HF/def2-QZVPP level of theory (the same as the $\left.+20.50 \mathrm{kcal} \mathrm{mol}{ }^{-1}\right) .{ }^{51}$ This summation can be regarded as an estimate of the extent of steric repulsion. ${ }^{50}$ It is noteworthy that $\mathrm{CH}_{4} @ \mathrm{C}_{60}$ is predicted to be unstable also by DFT if empirical dispersion corrections are not used. ${ }^{32,33}$ The non-dispersive correction due to electron correlation was small and repulsive $\left(\Delta E_{\text {non-disp }}^{\mathrm{C}}=+1.00 \mathrm{kcal} \mathrm{mol}^{-1}\right)$. As expected, London dispersion is the dominant intermolecular interaction mechanism. The magnitude of the $E_{\text {disp }}^{\mathrm{C}}$ term of $-29.96 \mathrm{kcal} \mathrm{mol}^{-1}$ was larger than the substantially repulsive Hartree-Fock interaction and the $\Delta E_{\text {non-disp }}^{\mathrm{C}}$ correction, resulting in an endohedral complex stabilization by $-8.47 \mathrm{kcal} \mathrm{mol}^{-1}$. However, a further attractive correction came from the contribution from perturbative triple excitations $\Delta E_{\text {int }}^{\mathrm{C}-(\mathrm{T})}$ that stabilized the complex by an additional estimated contribution of $-5.03 \mathrm{kcal} \mathrm{mol}^{-1}$. The correction from perturbative triples was important, given that it increased the net binding energy in the complex by nearly $60 \%$ (from -8.47 to $-13.50 \mathrm{kcal} \mathrm{mol}^{-1}$; see the inset in Fig. 3). Therefore, the final electronic interaction energy at the DLPNO-CCSD(T)/ cc-pVQZ $\left(\mathrm{CH}_{4}\right) / c c-p V T Z\left(\mathrm{C}_{60}\right)$ level of theory for the $\mathrm{CH}_{4} @ \mathrm{C}_{60}$ endohedral complex was $-13.50 \mathrm{kcal} \mathrm{mol}^{-1}$. The geometry preparation ("deformation energy") term was very small $\left(\Delta E_{\text {geo-prep }}=+0.03 \mathrm{kcal} \mathrm{mol}^{-1}\right) . \mathrm{C}_{60}$ is a rigid molecule and encapsulation of the $\mathrm{CH}_{4}$ guest had a negligible effect on its geometry (see Table 2). Our reference stabilization energy of $\Delta E=-13.47 \mathrm{kcal} \mathrm{mol}^{-1}$ was compared with the best reported estimates. For the $\mathrm{CH}_{4} @ \mathrm{C}_{60}$ complex, the most robust results have been reported by Pyykkö and coworkers. ${ }^{51}$ In that study interaction energies were obtained with supramolecular MP2 and its spin component scaled counterpart (SCS-MP2). Calculations were performed with the def2-TZVPP and def2QZVPP basis sets, interaction energies were corrected for basis set superposition error and extrapolated to the complete basis set limit. The obtained MP2 interaction energy of

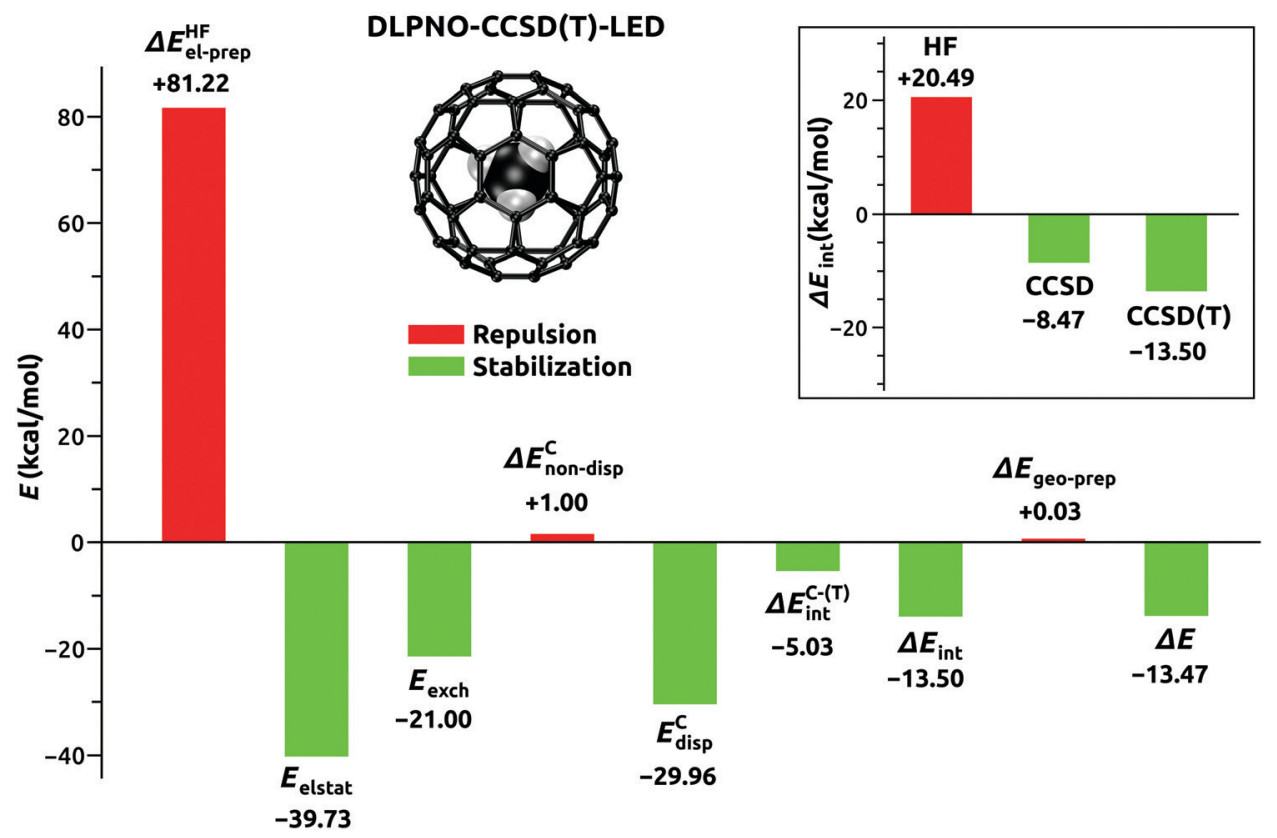

Fig. 3 Results of the DLPNO-CCSD(T)-LED/cc-pVQZ $\left(\mathrm{CH}_{4}\right) / \mathrm{cc}$-pVTZ( $\left.\mathrm{C}_{60}\right)$ local energy decomposition analysis for the $\mathrm{CH}_{4} \mathrm{QC} \mathrm{C}_{60}$ endohedral complex, energies are given in $\mathrm{kcal} \mathrm{mol}^{-1}$. Inset shows total interaction energies $\left(\Delta E_{\text {int }}\right)$ corresponding to the Hartree-Fock, CCSD, and CCSD(T) levels of theory. 
$-21.37 \mathrm{kcal} \mathrm{mol}^{-1}$ was clearly overestimated. The value obtained with SCS-MP2 $\left(-11.97 \mathrm{kcal} \mathrm{mol}^{-1}\right)$ was closer to the coupled cluster reference, but underestimated. These calculated interaction energies followed the pattern observed in previously reported benchmark calculations. For the $\mathrm{CH}_{4} \cdots \mathrm{C}_{6} \mathrm{H}_{6}$ dimer, MP2 overestimates the $\operatorname{CCSD}(\mathrm{T})$ interaction energy, as was shown by Ringer et al., ${ }^{80}$ and for the endohedral $\mathrm{CH}_{4} @ \mathrm{C}_{60}$ complex, this overestimation seems to be even more pronounced. The same trend of deviation was observed by Pyykkö and coworkers for dimers composed of atoms of noble gases and benzene $\left(\mathrm{Ng} \cdots \mathrm{C}_{6} \mathrm{H}_{6}\right)$, where MP2 overestimated the $\operatorname{CCSD}(\mathrm{T})$ reference interaction energies significantly, whereas SCS-MP2 was generally much closer to coupled cluster results, but consistently underestimated the interaction. ${ }^{51}$

Pyykkö and coworkers have also developed London-type formulas to estimate dispersion interaction energies in endohedral systems. $^{50,51}$ The input parameters to these formulas such as ionization potentials and polarizabilities can be readily computed at the DFT level. Using the data from the study of Pyykkö and coworkers $^{51}$ (Table 17, equations $69+86$ ) the dispersion energy estimate of $-17.33 \mathrm{kcal} \mathrm{mol}^{-1}$ was obtained for the $\mathrm{CH}_{4} @ \mathrm{C}_{60}$ complex. This energy was much smaller than for the DLPNO$\operatorname{CCSD}(\mathrm{T})$-LED $\left(-29.96 \mathrm{kcal} \mathrm{mol}^{-1}\right)$, and would not overcome the steric repulsion estimate of $+20.49 \mathrm{kcal} \mathrm{mol}^{-1}$, and the complex would not be estimated to be stabilized in that description.

In Fig. 4, energies are shown in relation to the energy barrier of $\mathrm{CH}_{4}$ insertion through the orifice of the open-cage $\mathrm{C}_{60}$. The model of open-fullerene is designed to match the molecule

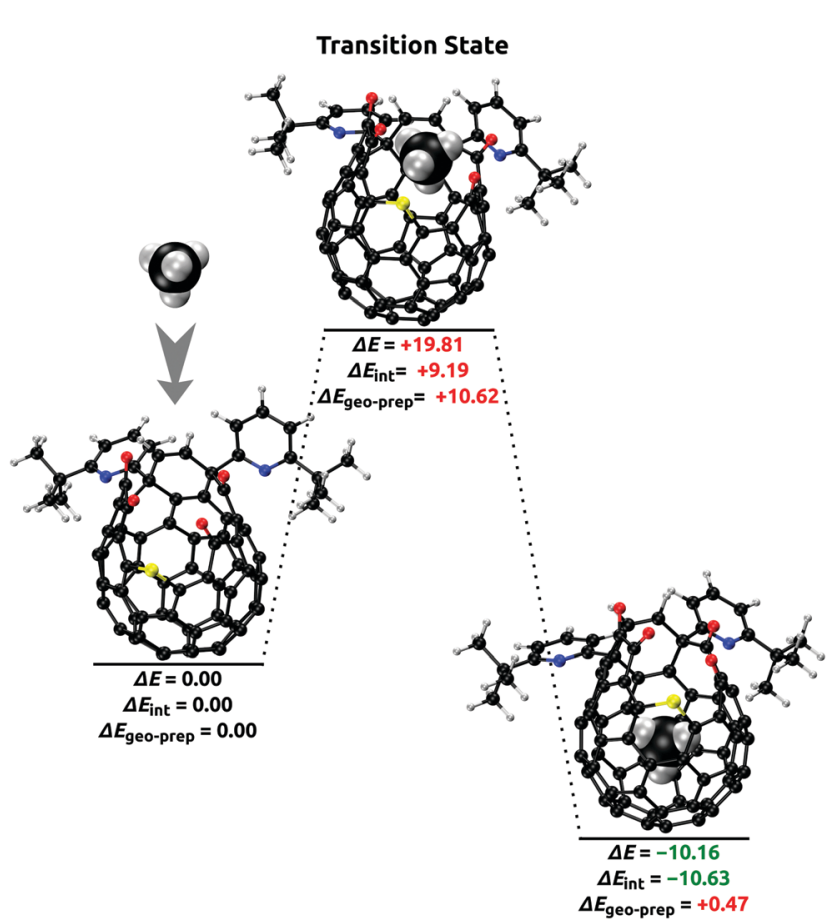

Fig. 4 DLPNO-CCSD(T)/cc-pVQZ $\left(\mathrm{CH}_{4}\right) / c c-p V D Z$ (open-fullerene) results for the calculations of the energy barrier of $\mathrm{CH}_{4}$ insertion $\left(\mathrm{kcal} \mathrm{mol}^{-1}\right)$. Molecular geometries of the free $\mathrm{CH}_{4}$, open-fullerene, transition state, and the $\mathrm{CH}_{4}$ @open-fullerene complex were optimized at the revPBE-D4/ pcseg-1 level. used by Whitby and coworkers ${ }^{20}$ in their successful synthesis of the $\mathrm{CH}_{4} @ \mathrm{C}_{60}$ endohedral complex. The insertion energy barrier was calculated at the DLPNO-CCSD(T)/cc-pVQZ $\left(\mathrm{CH}_{4}\right)$ / cc-pVDZ(open-fullerene) level of theory and was significant $\left(\Delta E=+19.81 \mathrm{kcal} \mathrm{mol}^{-1}\right)$, and in agreement with experimental observations that high pressure and elevated temperature conditions (1645 atm, $190{ }^{\circ} \mathrm{C}$ for $22 \mathrm{~h}$ ) are necessary to achieve a high degree of $\mathrm{CH}_{4}$ insertion. ${ }^{20}$ It is noteworthy that the electronic repulsive interaction at the orifice $\Delta E_{\text {int }}=$ $+9.19 \mathrm{kcal} \mathrm{mol}^{-1}$ amounted to only less than half of the insertion energy barrier. The remaining geometry preparation term corresponded to the energy needed to deform the opencage fullerene from its equilibrium geometry to the one optimal for $\mathrm{CH}_{4}$ insertion $\left(\Delta E_{\text {geo-prep }}=+10.62 \mathrm{kcal} \mathrm{mol}^{-1}\right)$. After insertion, the $\mathrm{CH}_{4}$ molecule is predicted to be stabilized inside the open-fullerene cage by $\Delta E=-10.16 \mathrm{kcal} \mathrm{mol}^{-1}$.

\section{Spectroscopic properties of $\mathrm{CH}_{4} @ \mathrm{C}_{60}$ in IR and UV-Vis}

Harmonic vibrational frequencies of the endohedral $\mathrm{CH}_{4} @ \mathrm{C}_{60}$ complex have been computed at the level of GGA and hybrid DFT approximations without using dispersion corrections, ${ }^{32,33}$ and at the Hartree-Fock level of theory. ${ }^{34}$ Hence, those frequencies were evaluated on structures corresponding to energy minima in a situation where London dispersion interactions had not been accounted for. In those studies the intensities in the resulting calculated IR and Raman spectra were not discussed as well. Therefore, we calculated the harmonic vibrational frequencies together with the respective IR absorption coefficients and Raman scattering factors for $\mathrm{CH}_{4}, \mathrm{C}_{60}$, and the $\mathrm{CH}_{4} @ \mathrm{C}_{60}$ complex at the revPBE-D4/pcseg-1 level of theory. Related frequencies, absorption coefficients and scattering factors are presented in Table 3.

The calculated vibrational frequencies of $\mathrm{C}_{60}$ were in very good agreement with experimental data and virtually unchanged upon $\mathrm{CH}_{4}$ encapsulation. This situation was in agreement with the experimental IR spectrum of $\mathrm{H}_{2} \mathrm{O} @ \mathrm{C}_{60}$, where the vibrational frequencies of the fullerene cage were the same as those of the free $\mathrm{C}_{60} \cdot{ }^{19}$ The calculated IR absorption coefficients and Raman scattering factors (for the fullerene cage) were predicted to be slightly affected by $\mathrm{CH}_{4}$ encapsulation and resulted on average in a $<5 \%$ loss in spectral intensity. Frequencies of the encapsulated $\mathrm{CH}_{4}$ on the other hand were blue shifted with respect to the free $\mathrm{CH}_{4}$ molecule, and were in agreement with previous theoretical predictions. ${ }^{33,34}$ Our results suggested that the triple degeneracy of the asymmetric bending and stretching IR modes (1287 and $3107 \mathrm{~cm}^{-1}$ ) of $\mathrm{CH}_{4}$ was partially removed due to the interaction with the cage. However, what was the most important, for both IR and Raman a substantial loss in spectral intensities for the encapsulated $\mathrm{CH}_{4}$ was revealed. This intensity loss was in line with experimental IR spectra of the $\mathrm{CH}_{4}$ @open-fullerene complex, where vibrations of the $\mathrm{CH}_{4}$ could not be observed. ${ }^{37}$ In addition, vibrational features of the $\mathrm{H}_{2} \mathrm{O}$ were very weak in the experimental IR spectrum of $\mathrm{H}_{2} \mathrm{O} @ \mathrm{C}_{60}$, and the potential screening effect of the fullerene cage was indicated. ${ }^{19,86}$ Dielectric measurements conducted at low temperature and IR spectra of $\mathrm{H}_{2} \mathrm{O} @ \mathrm{C}_{60}$ collected at liquid helium 
Table 3 Harmonic vibrational frequencies $\left(\nu ; \mathrm{cm}^{-1}\right)$, IR absorption coefficients $\left(A ; 10^{5} \mathrm{~cm} \mathrm{~mol}^{-1}\right)^{a}$ and Raman scattering factors $\left(S ; \AA^{4} \mathrm{amu}^{-1}\right)^{a}$ calculated at the revPBE-D4/pcseg-1 level of theory; ${ }^{b}$ experimental values for the free $\mathrm{CH}_{4}$ and $\mathrm{C}_{60}$ are shown in parentheses ${ }^{C}$

\begin{tabular}{|c|c|c|}
\hline $\mathrm{CH}_{4}$ & $\mathrm{C}_{60}$ & $\mathrm{CH}_{4} @ \mathrm{C}_{60}$ \\
\hline \multirow[t]{3}{*}{$\nu / A$} & $502(527) / 23.4$ & $501 / 22.0$ \\
\hline & $579(577) / 14.1$ & $581 / 13.7$ \\
\hline & $1201(1183) / 9.5$ & $1201 / 8.9$ \\
\hline \multirow[t]{4}{*}{$1287(1367) / 19.9$} & & $1296 / 0.3$ \\
\hline & & $1304 / 0.3$ \\
\hline & & $1332 / 0.3$ \\
\hline & $1456(1428) / 13.8$ & $1457 / 13.4$ \\
\hline \multirow[t]{3}{*}{$3107(3157) / 15.7$} & & $3218 / 0.1$ \\
\hline & & $3220 / 0.1$ \\
\hline & & $3223 / 0.1$ \\
\hline \multirow[t]{7}{*}{$\nu / S$} & $258(273) / 25.4$ & $263 / 24.2$ \\
\hline & $416(437) / 0.4$ & $421 / 0.4$ \\
\hline & $488(496) / 152.7$ & $491 / 149.7$ \\
\hline & $664(710) / 0.2$ & $664 / 0.2$ \\
\hline & $775(774) / 9.0$ & 775/9.0 \\
\hline & $1108(1099) / 14.7$ & $1108 / 12.7$ \\
\hline & $1264(1250) / 22.3$ & $1264 / 19.6$ \\
\hline \multirow[t]{5}{*}{$1287(1367) / 0.8$} & & $1296 / 0.7$ \\
\hline & & $1304 / 0.7$ \\
\hline & & $1332 / 0.7$ \\
\hline & $1444(1428) / 2.9$ & $1444 / 2.7$ \\
\hline & $1496(1470) / 365.0$ & $1496 / 348$ \\
\hline \multirow[t]{2}{*}{$1506(1583) / 21.4$} & & $1534 / 1.3$ \\
\hline & $1581(1575) / 59.1$ & $1580 / 52.4$ \\
\hline $2972(3026) / 160.1$ & & $3075 / 2.3$ \\
\hline \multirow[t]{3}{*}{$3107(3157) / 69.2$} & & $3218 / 0.5$ \\
\hline & & $3220 / 0.5$ \\
\hline & & $3223 / 0.3$ \\
\hline
\end{tabular}

${ }^{a}$ See ref. 83. ${ }^{b}$ Only the respective IR/Raman active modes $(A, S \geq 0.1)$ are shown. ${ }^{c}$ From ref. 84 and 85.

temperature have revealed that the dipole moment of the encapsulated $\mathrm{H}_{2} \mathrm{O}$ was $0.5 \pm 0.1 \mathrm{D},{ }^{87,88}$ which is about $25 \%$ of free $\mathrm{H}_{2} \mathrm{O}$ molecules (in agreement with theoretical predictions ${ }^{89}$ ). A very similar extent of dipole moment reduction has been observed for HF in HF@C 60 as well. ${ }^{90}$

The fullerene cage protects encapsulated species from the influence of the external electric field, and acts as a molecular Faraday cage. ${ }^{91,92}$ Such a screening effect can be assessed by calculating a difference between the dipole polarizability $(\alpha)$ of an endohedral complex, and the sum of polarizabilities of an isolated guest and the empty fullerene: ${ }^{93}$

$$
\Delta \alpha=\alpha\left(\mathrm{X} @ \mathrm{C}_{60}\right)-\left[\alpha(\mathrm{X})+\alpha\left(\mathrm{C}_{60}\right)\right]
$$

Negative $\Delta \alpha$ corresponds to the polarizability depression that results from the decrease of polarizability of the encapsulated guest. Therefore, the dielectric screening coefficient can be evaluated: ${ }^{93}$

$$
c=-\frac{\Delta \alpha}{\alpha(\mathrm{X})}
$$

To inspect these effects for the $\mathrm{CH}_{4} @ \mathrm{C}_{60}$ endohedral complex, the dipole polarizabilities of $\mathrm{CH}_{4}, \mathrm{C}_{60}$, and $\mathrm{CH}_{4} @ \mathrm{C}_{60}$ were calculated at the CAM-B3LYP/Sadlej-pVTZ level of theory. The range-separated and Coulomb-attenuating method called the CAM-B3LYP DFT approximation ${ }^{94}$ was shown to deliver accurate polarizabilities, ${ }^{95}$ and a balanced description of electronic excited states. ${ }^{96}$ The Sadlej-pVTZ basis set was specifically developed for calculations of polarizabilities and other electric molecular properties. ${ }^{97-99}$ The calculated polarizabilities and the respective values obtained from eqn (3) and (4) are shown in Table 4. The values for the polarizabilities for $\mathrm{CH}_{4}$ and $\mathrm{C}_{60}$ were in very good agreement with experimental data. The polarizability of the $\mathrm{CH}_{4} @ \mathrm{C}_{60}$ complex was predicted to be almost the same as that of the empty $\mathrm{C}_{60}$, which in turn was reflected in a substantial polarizability depression of $\Delta \alpha=-2.48$. The value for the dielectric screening coefficient $(c=0.97)$ indicated a particularly strong effect for the $\mathrm{CH}_{4} @ \mathrm{C}_{60}$ endohedral complex. The polarizability of the encapsulated $\mathrm{CH}_{4}$ molecule was essentially quenched.

The electronic excited state energies and absorption in the UV-vis domain were calculated at the CAM-B3LYP/cc-pVTZ level of theory with a time-dependent DFT (TD-DFT) within the efficient STD-DFT implementation of Bannwarth and Grimme. $^{102}$ Transition energies, wavelengths, and oscillator strengths for $\mathrm{C}_{60}$ and $\mathrm{CH}_{4} @ \mathrm{C}_{60}$ are shown in Table 5.

The predicted spectroscopic characteristics of $\mathrm{C}_{60}$ and $\mathrm{CH}_{4} @ \mathrm{C}_{60}$ were almost identical in the UV-vis range. Both entities exhibited the same transition energies. The oscillator strengths were marginally lower for the complex compared to the empty fullerene. These results were in agreement with experimental observations for $\mathrm{C}_{60}$ and $\mathrm{H}_{2} \mathrm{O} @ \mathrm{C}_{60}$. They display close to identical UV-vis spectra, despite revealing a slightly lower absorption for the complex. ${ }^{19}$ The data in Table 5 compare favorably with the experimental UV-vis spectrum of $\mathrm{C}_{60}$ in the gas phase. ${ }^{103}$ The set of three most intense bands at

Table 4 Dipole polarizabilities $\left(\alpha ; \AA^{3}\right)$ calculated at the CAM-B3LYP/ Sadlej-pVTZ level of theory; experimental values are shown in parentheses $^{a}$

$\begin{array}{ll}\mathrm{CH}_{4} & 2.57(2.60) \\ \mathrm{C}_{60} & 81.02(79 \pm 4) \\ \mathrm{CH}_{4} @ \mathrm{C}_{60} & 81.11 \\ & \\ \Delta \alpha & -2.48 \\ c & 0.97\end{array}$

${ }^{a}$ From ref. 100 and 101.

Table 5 Transition energies ( $E$; eV), corresponding wavelengths $(\lambda ; \mathrm{nm})$, and oscillator strengths $\left(f_{\text {osc }}\right)^{a}$ calculated at the CAM-B3LYP/cc-pVTZ level

\begin{tabular}{|c|c|c|c|c|c|}
\hline \multicolumn{3}{|l|}{$\underline{\mathrm{C}_{60}}$} & \multicolumn{3}{|c|}{$\mathrm{CH}_{4} @ \mathrm{C}_{60}$} \\
\hline$E$ & $\lambda$ & $f_{\text {osc }}$ & $E$ & $\lambda$ & $f_{\mathrm{osc}}$ \\
\hline 3.86 & 322 & 0.151 & 3.86 & 322 & 0.149 \\
\hline 4.14 & 300 & 0.384 & 4.14 & 300 & 0.379 \\
\hline 5.31 & 231 & 1.922 & 5.37 & 231 & 1.919 \\
\hline 6.28 & 198 & 0.228 & 6.28 & 198 & 0.222 \\
\hline 6.63 & 187 & 1.907 & 6.63 & 187 & 1.905 \\
\hline 7.38 & 168 & 0.407 & 7.38 & 168 & 0.378 \\
\hline 7.62 & 163 & 0.013 & 7.62 & 163 & 0.013 \\
\hline
\end{tabular}
of theory

${ }^{a}$ Transitions with oscillator strengths $f_{\text {osc }}>0.01$ are shown. 
$187 / 231 / 300 \mathrm{~nm}$ that reveal oscillator strengths of $1.907 / 1.922 /$ 0.384 correspond to the experimentally observed transitions at $205 / 257 / 330 \mathrm{~nm}$ that exhibit extinction coefficients of 4.8/3.5/ $0.9\left(10^{5} \mathrm{~L} \mathrm{~mole}^{-1} \mathrm{~cm}^{-1}\right) .{ }^{103}$ Hence, the pattern of UV-vis bands correlated well between theoretical predictions and the experimentally observed spectra, however, transition energies were overestimated (too short wavelengths) at the TD-DFT level of theory.

Because of the rich chemistry of the ionized fullerene species $\left(\mathrm{C}_{60}^{n+} ; n=1,2,3\right)$, it is interesting to compare the ionization potentials of the $\mathrm{C}_{60}$ and its endohedral complex. Ionized fullerenes exhibit a diversity of ionization mechanisms and a variety of reactions with potential implications to chemistry in the interstellar medium. ${ }^{104}$ The vertical ionization energies (VIE) for $\mathrm{C}_{60}$ and $\mathrm{CH}_{4} @ \mathrm{C}_{60}$ were calculated at the CAM-B3LYP/Sadlej-pVTZ level of theory according to:

$$
\mathrm{VIE}=E_{\text {cation }}^{n+}-E_{\text {neutral }}^{0} ; \quad n=1,2,3
$$

where $E_{\text {cation }}^{n+}$ and $E_{\text {neutral }}^{0}$ denote the total energies of the ionized and neutral species, respectively. They were calculated at the equilibrium geometry of the ground state. The calculations for ionized species involved an unrestricted (UDFT) formalism due to higher than singlet multiplicities. The obtained results indicated that the ionization potentials of the $\mathrm{CH}_{4} @ \mathrm{C}_{60}$ complex were almost identical to those of empty $\mathrm{C}_{60}$. The calculated VIE for $\mathrm{C}_{60}$ agreed very well with experimental data, as can be seen from the values in Table 6 .

\section{NMR properties of the $\mathrm{CH}_{4} @ \mathrm{C}_{60}$}

Fullerenes constitute the only known allotrope of carbon that can be dissolved in organic solvents at room temperature. ${ }^{106}$ Therefore, high resolution liquid-state NMR spectra of $\mathrm{C}_{60}$ and its endohedral complexes can be measured in common NMR solvents. ${ }^{107,108}$ Whitby and coworkers collected and analyzed ${ }^{1} \mathrm{H}$ and ${ }^{13} \mathrm{C}$ NMR spectra of the $\mathrm{CH}_{4} @ \mathrm{C}_{60}$ complex dissolved in 1,2-dichlorobenzene. ${ }^{20}$ For prediction of such spectra with quantum chemistry methods, a robust model including subtle interactions of the fullerene cage with solvent molecules is important. Hence, we constructed systems composed of the $\mathrm{C}_{60}$ and $\mathrm{CH}_{4} @ \mathrm{C}_{60}$ explicitly solvated by 25 molecules of 1,2dichlorobenzene, whereas solvent effects at the outer sphere were accounted implicitly by a polarizable continuum model (PCM) assuming a dielectric constant $\varepsilon=9.93$. The initial configuration was obtained with the Packmol software, ${ }^{109}$ and

Table 6 Vertical ionization energies (VIE; eV) calculated at the CAMB3LYP/Sadlej-pVTZ level of theory; experimental values are shown in parentheses $^{a}$

\begin{tabular}{ll}
\hline $\mathrm{C}_{60}^{+}$ & $7.89(7.65 \pm 0.20)$ \\
$\mathrm{C}_{60}^{++}$ & $18.82(18.98 \pm 0.25)$ \\
$\mathrm{C}_{60}^{+++}$ & $32.81(35.8 \pm 0.3)$ \\
$\mathrm{CH}_{4} @ \mathrm{C}_{60}^{+}$ & 7.90 \\
$\mathrm{CH}_{4} @ \mathrm{C}_{60}^{++}$ & 18.83 \\
$\mathrm{CH}_{4} @ \mathrm{C}_{60}^{+++}$ & 32.83 \\
${ }^{a}$ From ref. 105. & \\
\end{tabular}

the coordinates were energy optimized at the revPBE-D4/pcseg$1\left(\mathrm{CH}_{4}, \mathrm{C}_{60}\right) /$ pcseg- $0\left(\mathrm{C}_{6} \mathrm{H}_{4} \mathrm{Cl}_{2}\right)$ level of theory up to the energy change of $<5 \times 10^{-6} E_{\mathrm{h}}$; see Fig. 5 .

The ${ }^{1} \mathrm{H}$ and ${ }^{13} \mathrm{C}$ nuclear magnetic shielding tensors ${ }^{110,111}(\sigma$; assessed with the GIAO approach ${ }^{112}$ ) and indirect nuclear spinspin coupling constants $(J)$ were calculated at the level of PBE0 DFT approximation. ${ }^{113}$ The calculations were performed with segmented pcS-1 and pcJ-1 basis sets, which have been specifically developed to provide fast convergence towards the Kohn-Sham limit for NMR shieldings and spin-spin couplings. ${ }^{114,115}$ The chosen setup represents a reasonable compromise for the calculations of ${ }^{1} \mathrm{H} /{ }^{13} \mathrm{C}$ NMR parameters when compared to more accurate methods given the size of the system. ${ }^{116,117}$ For solvent molecules, the pcseg-0 basis set was used. The calculations of NMR observables involved all electrons (no frozen core) and very tight grids (GridX8 Grid7). The calculated isotropic ${ }^{1} \mathrm{H} /{ }^{13} \mathrm{C}$ NMR shielding:

$$
\sigma=\frac{\sigma_{x x}+\sigma_{y y}+\sigma_{z z}}{3}
$$

was converted into isotropic NMR chemical shift $\delta$ according to:

$$
\delta_{j}=\sigma_{\mathrm{CH}_{4}(\text { gas })}^{\text {ref,calc }}-\sigma_{j}^{\text {calc }}+\delta_{\mathrm{CH}_{4}(\text { gas })}^{\text {ref,exp }}
$$

where $\delta_{j}$ and $\sigma_{j}$ correspond to the chemical shift and shielding of an atom of interest $j$, whereas $\sigma_{\mathrm{CH}_{4}(\mathrm{gas})}^{\text {ref,calc }}$ and $\delta_{\mathrm{CH}_{4} \text { (gas) }}^{\text {ref,exp }}$ represent the calculated shielding and experimental shift of the reference, respectively. The $\mathrm{CH}_{4}$ molecule was used as a reference since its proton and carbon chemical shifts measured in the gas phase are available. ${ }^{118}$ Shifts of chemically equivalent atoms were averaged. Spin-spin coupling constants were represented as a sum of four physical contributions: the Fermi contact (FC), spindipole (SD), paramagnetic spin-orbit (PSO), and diamagnetic spin-orbit (DSO) terms.

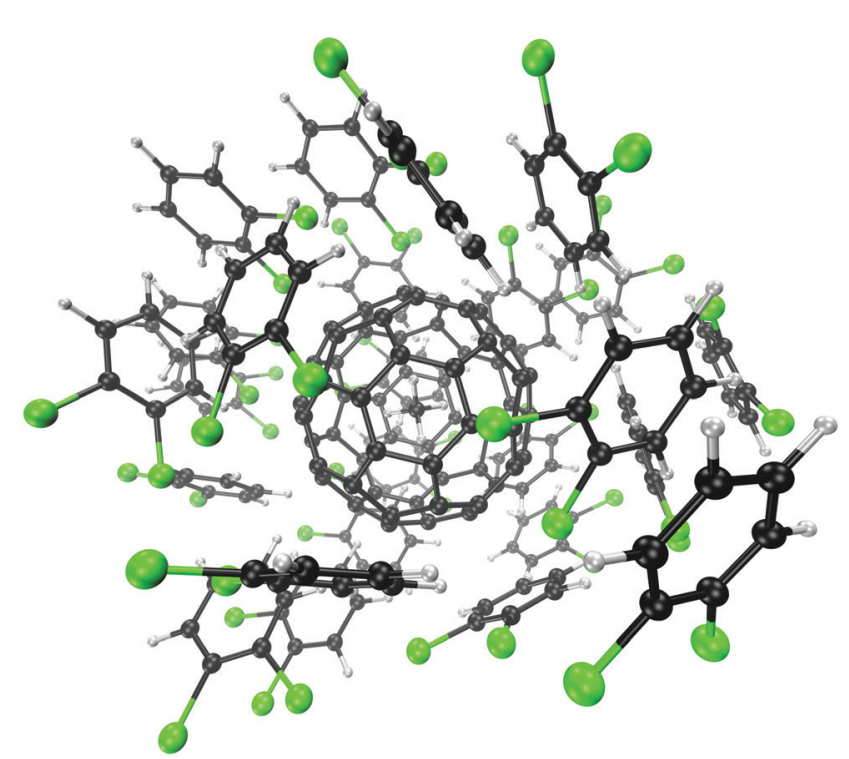

Fig. 5 Model of the $\mathrm{CH}_{4} \mathrm{aC}_{60}$ endohedral complex solvated by 25 molecules of 1,2-dichlorobenzene. 
The calculated ${ }^{1} \mathrm{H}$ and ${ }^{13} \mathrm{C}$ NMR chemical shifts as well as the ${ }^{1} \mathrm{H}-{ }^{13} \mathrm{C}$ spin-spin couplings presented in Table 7 revealed very good agreement with experimental data. For protons in the $\mathrm{CH}_{4}$ molecule, the change in chemical shift $(\Delta \delta)$ upon encapsulation in $\mathrm{C}_{60}$ was predicted to be $-7.54 \mathrm{ppm}$, which compared very well to $-7.88 \mathrm{ppm}$ observed in an experiment. ${ }^{20}$ This change on encapsulation is associated with the NMR shielding inside the fullerene cage, where the locally induced magnetic fields counteract the applied external field of the NMR instrument. The corresponding effect for the ${ }^{13} \mathrm{C}$ in $\mathrm{CH}_{4}$ was slightly smaller, as revealed by the calculated and experimental $\Delta \delta$ values of -5.87 and $-4.98 \mathrm{ppm}$, respectively. For carbon atoms of the fullerene cage, the presence of endohedral $\mathrm{CH}_{4}$ results in a deshielding of the ${ }^{13} \mathrm{C}$ NMR signal. Therefore, this effect is opposite to that observed for the ${ }^{13} \mathrm{CH}_{4}$ inside the cage. The calculated ${ }^{13} \mathrm{C}$ deshielding of the cage of $+0.51 \mathrm{ppm}$ was in excellent agreement with the experimental value of $+0.52 \mathrm{ppm}^{20}$ The spin-spin coupling constant ${ }^{1} J_{\mathrm{HC}}$ in the $\mathrm{CH}_{4}$ was dominated by the Fermi-contact (FC) mechanism. The calculated coupling strength of ${ }^{1} J_{\mathrm{HC}}=126.4 \mathrm{~Hz}$ for the free $\mathrm{CH}_{4}$ was close to the experimental value of $125.3 \mathrm{~Hz}^{119}$ Encapsulation of $\mathrm{CH}_{4}$ in $\mathrm{C}_{60}$ had little effect on the ${ }^{1} J_{\mathrm{HC}}$, and the calculated value of $124.1 \mathrm{~Hz}$ was very close to the experimentally determined $124.3 \mathrm{~Hz}^{20}$ Therefore, our theoretical model predicts correctly the sign and the small magnitude of the $\Delta J$. The small change of the coupling was consistent with negligible deformation of the $\mathrm{CH}_{4}$ geometry upon encapsulation.

\section{Complexes with noble gases $\mathrm{Ng} @ \mathrm{C}_{60}(\mathrm{Ng}=\mathrm{He}, \mathrm{Ne}, \mathrm{Ar}, \mathrm{Kr})$}

The efficient DLPNO-CCSD(T) setup designed for probing intermolecular interactions in the $\mathrm{CH}_{4} @ \mathrm{C}_{60}$ complex was also used to obtain reference interaction energies for endohedral complexes with atoms of noble gases $\left(\mathrm{Ng} @ \mathrm{C}_{60} ; \mathrm{He}, \mathrm{Ne}, \mathrm{Ar}, \mathrm{Kr}\right)$.

Table 7 Isotropic ${ }^{1} \mathrm{H} /{ }^{13} \mathrm{C}$ NMR chemical shifts $\left(\delta\right.$; ppm) and ${ }^{1} \mathrm{H}-{ }^{13} \mathrm{C}$ spinspin coupling constants $\left({ }^{1} \mathrm{~J}_{\mathrm{HC}} ; \mathrm{Hz}\right)$ calculated at the PBEO/pcS-1 and PBEO/ pcJ-1 level of theory, respectively; experimental values are shown in parentheses $^{a}$

\begin{tabular}{|c|c|c|c|}
\hline & $\mathrm{CH}_{4}$ & $\mathrm{C}_{60}$ & $\mathrm{CH}_{4} @ \mathrm{C}_{60}$ \\
\hline $\begin{array}{l}\mathrm{C}^{1} \underline{\mathrm{H}}_{4} \\
\delta \\
\Delta \delta\end{array}$ & $\operatorname{Ref}(2.17)$ & & $\begin{array}{l}-5.37(-5.71) \\
-7.54(-7.88)\end{array}$ \\
\hline $\begin{array}{l}{ }^{13} \mathrm{CH}_{4} \\
\delta \\
\Delta \delta\end{array}$ & $\operatorname{Ref}(-8.65)$ & & $\begin{array}{l}-14.52(-13.63) \\
-5.87(-4.98)\end{array}$ \\
\hline $\begin{array}{l}{ }^{13} \mathrm{C}_{60} \\
\delta \\
\Delta \delta\end{array}$ & & $143.99(142.68)$ & $\begin{array}{l}144.50(143.20) \\
+0.51(+0.52)\end{array}$ \\
\hline $\begin{array}{l}{ }^{1} J_{\mathrm{HC}}(\mathrm{FC}) \\
{ }^{1} J_{\mathrm{HC}}(\mathrm{SD}) \\
{ }^{1} J_{\mathrm{HC}}(\mathrm{PSO}) \\
{ }^{1} J_{\mathrm{HC}}(\mathrm{DSO}) \\
{ }^{1} J_{\mathrm{HC}} \\
\Delta J\end{array}$ & $\begin{array}{l}124.4 \\
0.2 \\
1.6 \\
0.2 \\
126.4(125.3)\end{array}$ & & $\begin{array}{l}121.4 \\
0.2 \\
0.5 \\
2.0 \\
124.1(124.3) \\
-2.3(-1.0)\end{array}$ \\
\hline
\end{tabular}

${ }^{a}$ From ref. 20, 118 and 119.
Hence, in this section, we compared our coupled cluster results to previously reported estimates at lower levels of theory. In Table 8, interaction energies $\left(\Delta E_{\text {int }}\right)$ calculated at the DLPNO$\operatorname{CCSD}(\mathrm{T}) / \mathrm{cc}-\mathrm{pVQZ}(\mathrm{Ng}) / \mathrm{cc}-\mathrm{pVTZ}\left(\mathrm{C}_{60}\right)$ level of theory are presented together with values from the MP2/SCS-MP2 calculations by Pyykkö and coworkers, ${ }^{51}$ and from the DFTSAPT calculations by Hesselmann and Korona. ${ }^{49}$ The MP2 method exhibited the most unbalanced performance. The associated interaction energies for $\mathrm{He}$ was too low with this method, for Ne they were quite reasonable (accidentally), but those for Ar and $\mathrm{Kr}$ were severely overestimated. These trends resembled those observed for values derived with the MP2 method for the $\mathrm{CH}_{4} @ \mathrm{C}_{60}$ complex. The spin component scaled variant (SCS-MP2) displayed an improved description. Although interaction energies for $\mathrm{He}$ and $\mathrm{Ne}$ were too low, the result for Ar was close to the coupled cluster reference, and the overestimation for $\mathrm{Kr}$ was not as severe as with the MP2. The situation with the DFT-SAPT results was more complex and somewhat difficult to judge. On the one hand, all interaction energies for these systems obtained with the DFT-SAPT were consistently underestimated when compared to the DLPNO-CCSD $(\mathrm{T})$ values. On the other hand, the performance of the DFT-SAPT was consistent and well balanced across the $\mathrm{He}, \mathrm{Ne}, \mathrm{Ar}$, and $\mathrm{Kr}$ complexes. This complexity became apparent when the results of DLPNO-CCSD(T) were plotted against the DFT-SAPT counterpart in Fig. 6a. The correlation between the two approaches was very good, despite the consistently underestimated interaction energies by the latter. For comparison, the correlation with the SCS-MP2 data shown in panel b was much worse and significantly less convincing.

In Table 9, estimations of dispersion contributions to the interaction energy for the $\mathrm{Ng@C_{60 }}$ complexes are presented for different methods of calculations. The dispersion contributions $\left(E_{\text {disp }}^{\mathrm{C}}\right)$ from the DLPNO-CCSD(T)-LED were in good agreement with the dispersion components from the DFT-SAPT for all four considered complexes. Hence, it was concluded that the DFT-SAPT compared favorably to the DLPNO-CCSD(T)-LED for prediction of the dispersion interaction in fullerene complexes. This favorable comparison for DFT-SAPT is illustrated in Fig. 7a where results of DLPNO-CCSD(T) and DFT-SAPT are plotted against each other. Therefore, the too low interaction energies

Table 8 Interaction energies $\left(\Delta E_{\text {int }}\right)$ calculated at the DLPNO-CCSD $(T) /$

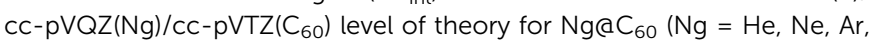
$\mathrm{Kr}$ ) complexes compared to supramolecular MP2/SCS-MP2 ${ }^{a}$ and DFT$\mathrm{SAPT}^{b}$ results; energies in $\mathrm{kcal} \mathrm{mol}^{-1}$

\begin{tabular}{lllll}
\hline Method & $\mathrm{He}$ & $\mathrm{Ne}$ & $\mathrm{Ar}$ & $\mathrm{Kr}$ \\
\hline MP2 & -2.63 & -5.40 & -19.49 & -26.80 \\
SCS-MP2 & -1.86 & -3.75 & -12.92 & -16.98 \\
DFT-SAPT & -1.58 & -2.85 & -7.87 & -8.26 \\
DLPNO-CCSD(T) & -4.97 & -6.56 & -12.30 & -13.39
\end{tabular}

${ }^{a}$ Two-point extrapolation to the CBS limit based on the def2-TZVPP/ def2-QZVPP basis sets; results from ref. $51 .{ }^{b}$ DFT-SAPT calculations with the PBEac functional, aug-cc-pVDZ(He,Ne), aug-cc-pVTZ(Ar, $\mathrm{Kr})$, and TZVP $(\mathrm{C})$ basis sets; results from ref. 49. 


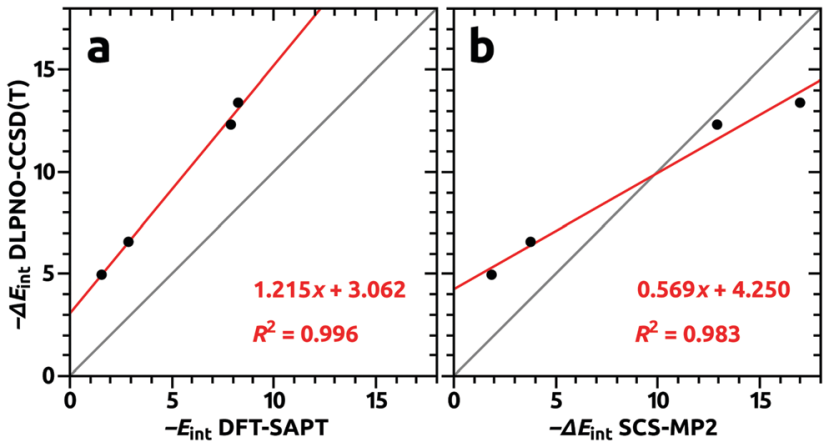

Fig. 6 Interaction energies $\left(\Delta E_{\text {int }}\right)$ calculated at the DLPNO-CCSD(T)/CC$p V Q Z(N g) / c c-p V T Z\left(C_{60}\right)$ level of theory plotted against the results from DFT-SAPT (a), ${ }^{49}$ and supramolecular SCS-MP2 (b). ${ }^{51}$ The grey line corresponds to the ideal correlation $y=x$, and the red line to the linear regression fit.

obtained with the DFT-SAPT for the complexes with noble gases did not originate from an inappropriate description of the dispersive part of the interaction, but resulted from deficiencies in the remaining components of the interaction energy. Analysis with DLPNO-CCSD(T)-LED revealed significant contributions from perturbative triples $\left(\Delta E_{\text {int }}^{\mathrm{C}-(\mathrm{T})}\right)$, and yet, for small guests $(\mathrm{He}, \mathrm{Ne})$ for which repulsive interaction at the Hartree-Fock level $\left(\Delta E_{\text {el-prep }}^{\mathrm{HF}}+E_{\text {elstat }}+E_{\text {exch }}\right)$ is small, the nondispersive corrections due to electron correlation $\left(\Delta E_{\text {non-disp }}^{\mathrm{C}}\right)$ were attractive.

The dispersion interaction as predicted with London-type formulas by Pyykkö and coworkers were substantially underestimated when compared to the DLPNO-CCSD(T)-LED results, although a linear trend with the latter was revealed; see Table 9 and Fig. 7b. This underestimation indicates that the sum of the dipole-dipole and quadrupole-quadrupole terms in the "Pyykkö model 2010" (eqn $69+72$ from ref. 51) was not sufficient, and that it is necessary to include higher order multipole-multipole contributions to obtain better agreement with high-level quantum chemistry methods. ${ }^{49,51}$

Table 9 Estimates of dispersion interaction in the $\mathrm{NgaC}_{60}(\mathrm{Ng}=\mathrm{He}, \mathrm{Ne}$, $\mathrm{Ar}, \mathrm{Kr}$ ) complexes from London-type formulas by Pyykkö and from the DFT-SAPT ${ }^{b}$ compared to the DLPNO-CCSD(T)-LED results; energies in kcal $\mathrm{mol}^{-1}$

\begin{tabular}{lllll}
\hline Method & $\mathrm{He}$ & $\mathrm{Ne}$ & \multicolumn{1}{l}{$\mathrm{Ar}$} & $\mathrm{Kr}$ \\
\hline Pyykkö model 2007 & -1.31 & -2.44 & -9.22 & -13.40 \\
Pyykkö model 2010 & -1.31 & -2.48 & -10.53 & -16.27 \\
DFT-SAPT (disp) & -2.57 & -5.28 & -21.96 & -33.89 \\
& & & & \\
DLPNO-CCSD(T)-LED & & & & \\
$\Delta E_{\text {el-prep }}^{\mathrm{HF}}$ & +2.38 & +10.65 & +52.47 & +97.34 \\
$E_{\text {elstat }}$ & -1.13 & -7.09 & -32.44 & -61.25 \\
$E_{\text {exch }}$ & -0.69 & -2.05 & -10.75 & -18.97 \\
$\Delta E_{\text {non-disp }}^{\mathrm{C}}$ & -2.30 & -1.02 & +0.98 & +2.14 \\
$E_{\text {disp }}^{\mathrm{C}}$ & -2.45 & -6.05 & -19.45 & -28.68 \\
$\Delta E_{\text {int }}^{\mathrm{C}-(\mathrm{T})}$ & -0.78 & -0.99 & -3.11 & -3.97
\end{tabular}

${ }^{a}$ Results with London-type formula for dispersion interaction in endohedral systems, model 2007 from Table 2 column 5 in ref. 50, model 2010 equations $69+72$ from ref. $51{ }^{b}{ }^{b}$ DFT-SAPT results from ref. 49.

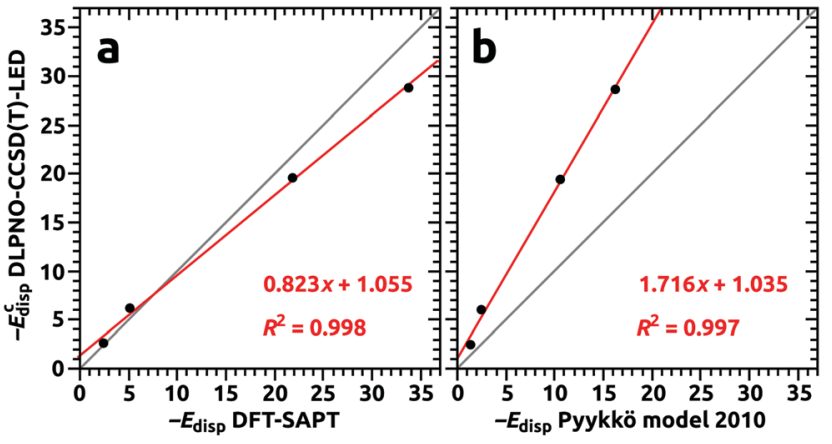

Fig. 7 Dispersion interaction energy $E_{\text {disp }}^{C}$ from DLPNO-CCSD(T)-LED decomposition compared to that obtained with the DFT-SAPT (a), ${ }^{49}$ and (b) with the London-type formula by Pyykkö. ${ }^{51}$ The grey line corresponds to the ideal correlation $y=x$, and the red line to the linear regression fit.

\section{The $\mathrm{He}_{2} @ \mathrm{C}_{60}$ trimer}

The existence of the $\mathrm{He}_{2} @ \mathrm{C}_{60}$ trimer, where two helium atoms are encapsulated inside the $\mathrm{C}_{60}$ was discovered with ${ }^{3} \mathrm{He}$ NMR by Rabinovitz and coworkers. ${ }^{120}$ The observed $\mathrm{He}_{2} @ \mathrm{C}_{60}$ : $\mathrm{He}_{0} \mathrm{C}_{60}$ ratio of $1: 200$ was 10 times smaller than that for $\mathrm{He}_{2} @ \mathrm{C}_{70}: \mathrm{He} @ \mathrm{C}_{70}(1: 20)$. This reduction suggests that the smaller cavity of $\mathrm{C}_{60}$ was significantly less suited for the encapsulation of two $\mathrm{He}$ atoms as compared to the $\mathrm{C}_{70}$ fullerene.

The stability of the $\mathrm{He}_{2} @ \mathrm{C}_{60}$ trimer was studied with quantum chemistry methods by Darzynkiewicz \& Scuseria, ${ }^{30}$ Krapp \& Franking, ${ }^{121}$ and Hesselmann \& Korona. ${ }^{49}$ However, all methods applied, including DFT, MP2, SCS-MP2, and DFT-SAPT predicted repulsive interaction in the range from +1.13 to $+10.23 \mathrm{kcal} \mathrm{mol}^{-1}$, depending on the method and the basis sets used. Hence, theoretical investigations reported so far suggest that $\mathrm{He}_{2} @ \mathrm{C}_{60}$ is thermodynamically unstable towards loss of the noble gas atom, in stark contrast to the experimental observation.

To gain insight into this challenging system and confront the discrepancy between theory and experiment with the DLPNO-CCSD(T) approach, a relaxed potential energy surface scan at the revPBE-D4/pcseg-1 level of theory was performed for the $\mathrm{He}_{2} @ \mathrm{C}_{60}$. The He-He distance was sampled with a $0.02 \AA$ increment, and for each step all other coordinates were subjected to unconstrained optimization. Subsequently, singlepoint DLPNO-CCSD(T) calculations were performed on the resulting geometries to locate the "true" energy minimum; see Fig. 8.

At the DLPNO-CCSD(T)/cc-pVQZ(He)/cc-pVTZ $\left(\mathrm{C}_{60}\right)$ level of theory, the equilibrium $\mathrm{He}-\mathrm{He}$ distance inside $\mathrm{C}_{60}$ was $1.94 \AA$. This distance was not only substantially shorter than that of $3.00 \AA$ A calculated for the free $\mathrm{He}_{2}$ dimer, but it corresponded to a clearly repulsive regime for the latter. Our result was close to the value of $1.95 \AA$ obtained by Krapp \& Franking ${ }^{121}$ at the DFT BP86/TZVPP level, and slightly shorter than $1.98 \AA$ A estimated by Kryachko et al. at the DFT M062X/6-31G(d) level. ${ }^{122}$ In agreement with the analysis in the latter work, we observed that the $\mathrm{He}_{2}$ dimer inside the $\mathrm{C}_{60}$ was fractionally ionized by $+0.0141|e|$ (Mulliken charge). The corresponding effect for the 


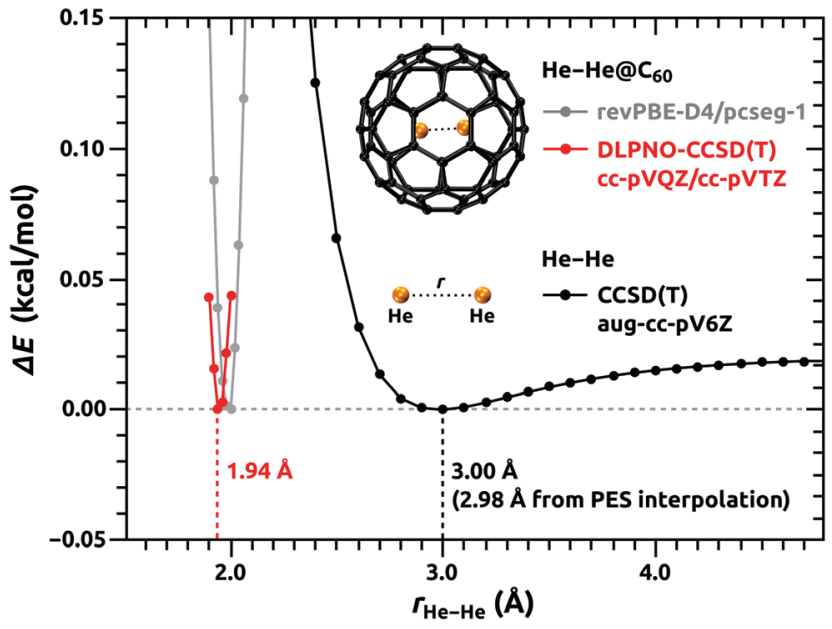

Fig. 8 CCSD(T)/aug-cc-pV6Z energy difference upon He-He distance change for the isolated $\mathrm{He}_{2}$ dimer (black curve) and that for the $\mathrm{He}_{2}$ dimer confined inside the $\mathrm{C}_{60}$ cavity (red curve) calculated at the DLPNO$\operatorname{CCSD}(T) / c c-p V Q Z\left(\mathrm{He}_{2}\right) / c c-p V T Z\left(\mathrm{C}_{60}\right)$ level of theory, where each point on the graph corresponds to the single-point coupled cluster calculation for the $\mathrm{He}_{2} \mathrm{aC}_{60}$ molecular geometry resulting from the relaxed potential energy surface scan along the $\mathrm{He}-\mathrm{He}$ distance at the revPBE-D4/pcseg-1 level (shown in grey). Values on the $y$ axis are normalized so that the energy minimum associated with the equilibrium $\mathrm{He}-\mathrm{He}$ distance of the respective system appears at $0.00 \mathrm{kcal} \mathrm{mol}^{-1}$.

case of a single $\mathrm{He}$ atom in the $\mathrm{He} @ \mathrm{C}_{60}$ complex was +0.0036 $|e|$; hence, comparably smaller. Note that the interaction well for the isolated $\mathrm{He}_{2}$ dimer was relatively shallow, whereas the relation of potential energy change upon $\mathrm{He}-\mathrm{He}$ distance variation was very steep for the $\mathrm{He}_{2} @ \mathrm{C}_{60}$ trimer.

For the equilibrium distance $r_{\mathrm{He}-\mathrm{He}}=1.94 \AA$ inside $\mathrm{C}_{60}$ the stabilization energy $\Delta E_{\text {int }}$ of the $\mathrm{He}_{2} @ \mathrm{C}_{60}$ trimer:

$$
\Delta E_{\text {int }}=E_{X Y Z}^{X Y Z}(X Y Z)-\left(E_{X}^{X Y Z}(X Y Z)+E_{Y}^{X Y Z}(X Y Z)+E_{Z}^{X Y Z}(X Y Z)\right)
$$

evaluated at the DLPNO-CCSD(T)/cc-pVQZ $\left(\mathrm{He}_{2}\right) / \mathrm{cc}-\mathrm{pVTZ}\left(\mathrm{C}_{60}\right)$ level of theory was $-1.43 \mathrm{kcal} \mathrm{mol}^{-1}$. Noteworthy was that the stabilization energy for the $\mathrm{He}_{2} @ \mathrm{C}_{60}$ trimer at the DLPNO$\operatorname{CCSD}(\mathrm{T})$ level of theory was almost as high as for the complex with a single $\mathrm{He}$ atom with the DFT-SAPT. The ab initio calculations predicted the $\mathrm{He}_{2} @ \mathrm{C}_{60}$ trimer to be stable, which is in agreement with experimental observations.

\section{Comparison of the DLPNO-CCSD(T) and HFLD approaches}

Recently the "Hartree-Fock + London dispersion" (HFLD) approach was introduced by Bistoni and coworkers ${ }^{123}$ as an efficient alternative to the DLPNO-CCSD(T) method when considering large molecular systems. Within the HFLD approach the interaction energy can be written as:

$$
\Delta E_{\mathrm{int}}=\Delta E_{\mathrm{int}}^{\mathrm{HF}}+E_{\mathrm{disp}}^{\mathrm{C}}
$$

where the $E_{\text {disp }}^{\mathrm{C}}$ term is extracted from the DLPNO-CCSD-LED calculation with only interfragment pairs included in the coupled cluster treatment. Hence, the HFLD approach can be considered as an extreme case of the multilevel DLPNO-CCSD
Table 10 Interaction energies and dispersion contributions for the $\mathrm{X}\left(\mathrm{C}_{60}\right.$ $\left(\mathrm{X}=\mathrm{He}, \mathrm{Ne}, \mathrm{Ar}, \mathrm{Kr}, \mathrm{CH}_{4}\right.$ ) complexes calculated with the DLPNO-CCSD(T) and HFLD ${ }^{a}$ methods using $c c-p V Q Z(X) / c c-p V T Z\left(C_{60}\right)$ basis sets; energies in $\mathrm{kcal} \mathrm{mol}^{-1}$

\begin{tabular}{llllll}
\hline Method & $\mathrm{He}$ & $\mathrm{Ne}$ & $\mathrm{Ar}$ & $\mathrm{Kr}$ & $\mathrm{CH}_{4}$ \\
\hline HFLD & & & & & \\
$\Delta E_{\text {int }}$ & -1.85 & -3.65 & -12.55 & -14.25 & -11.28 \\
$E_{\text {disp }}^{\mathrm{C}}$ & -2.40 & -5.16 & -21.82 & -31.35 & -31.77 \\
\multicolumn{2}{l}{ DLPNO-CCSD(T) } & & & & \\
$\Delta E_{\text {int }}$ & -4.97 & -6.56 & -12.30 & -13.39 & -13.50 \\
$E_{\text {disp }}^{\mathrm{C}}$ & -2.45 & -6.05 & -19.45 & -28.68 & -29.96
\end{tabular}

${ }^{a}$ HFLD computations were performed with the same setup as the DLPNO-CCSD $(\mathrm{T})$ counterparts (i.e. with TightPNO interfragment truncation thresholds).

calculation, ${ }^{59}$ where only interfragment pair correlation energies are considered, whereas the intrafragment part of the correlation energy is neglected (Hartree-Fock level). This approach together with the omission of triples correction leads to substantial computational savings. The surprisingly good performance of the HFLD scheme for the systems where this method has been tested so far ${ }^{123}$ originated from the fact that the $\Delta E_{\text {non-disp }}^{\mathrm{C}}$ and $\Delta E_{\mathrm{int}}^{\mathrm{C}-(\mathrm{T})}$ contributions of the correlation binding energy usually were small and of opposite signs, hence, they more or less canceled each other out. Therefore, omitting these two terms altogether provided estimates of the interaction energy that were close to the "full" DLPNO-CCSD(T) result. To inspect the reliability of this approach for endohedral complexes of fullerenes, the interaction energies for the systems considered in this work (X@ $\mathrm{C}_{60} ; \mathrm{X}=\mathrm{He}, \mathrm{Ne}, \mathrm{Ar}, \mathrm{Kr}, \mathrm{CH}_{4}$ ) were calculated. Results from the HFLD scheme are compared to those obtained at the DLPNO-CCSD(T) level; see Table 10 and Fig. 9.

Two observations can be made: (i) the data revealed a rather moderate accuracy of the HFLD method for the total interaction energies when compared to the DLPNO-CCSD(T) (see Fig. 9 panel a), which in turn indicated that the $\Delta E_{\text {non-disp }}^{\mathrm{C}}$ and $\Delta E_{\mathrm{int}}^{\mathrm{C}-(\mathrm{T})}$ contributions are important for an accurate description of endohedral fullerene complexes, (ii) the agreement for dispersion interaction components $E_{\text {disp }}^{\mathrm{C}}$ obtained with the
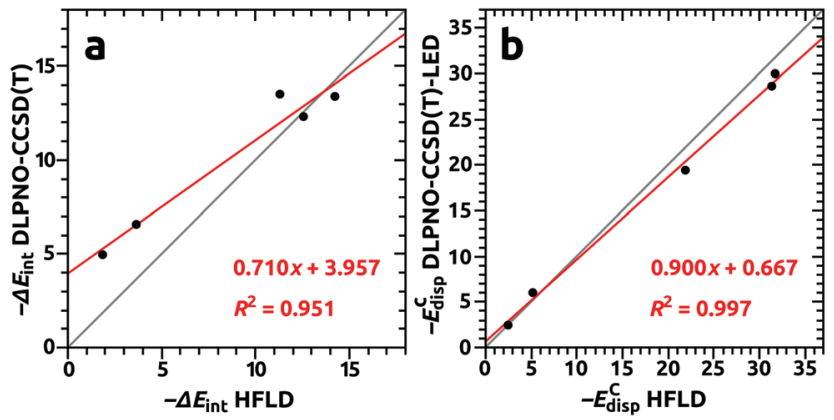

Fig. 9 Interaction energies (a) and dispersion interaction contributions (b) calculated within the DLPNO-CCSD(T) and HFLD schemes plotted against each other. The grey line corresponds to the ideal correlation $y=x$, and the red line to the linear regression fit. 
HFLD and DLPNO-CCSD(T)-LED approaches was very good (see Fig. 9 panel b). This agreement suggests that the HFLD scheme can be used as a nonempirical quantum mechanical method to obtain reliable estimates of the dispersion interaction contribution for large systems, where the accurate DLPNO-CCSD $(\mathrm{T})$ treatment is no longer affordable.

\section{Conclusions}

The reference interaction energies for endohedral complexes of the $\mathrm{C}_{60}$ fullerene with $\mathrm{He}, \mathrm{Ne}, \mathrm{Ar}, \mathrm{Kr}$, and $\mathrm{CH}_{4}$ were calculated at the DLPNO-CCSD(T) level of theory and decomposed into physical contributions with the LED scheme. An accurate and efficient multilevel DLPNO-CCSD(T) setup was proposed, which was applicable to routine studies of endohedral complexes of $\mathrm{C}_{60}$ and larger fullerenes. Calculated molecular properties of the $\mathrm{CH}_{4} @ \mathrm{C}_{60}$ complex revealed that the IR and Raman bands of the endohedral $\mathrm{CH}_{4}$ were essentially "silent" due to the dielectric screening effect of the $\mathrm{C}_{60}$, which acted as a molecular Faraday cage. Absorption spectra in the UV-vis and ionization potentials of $\mathrm{C}_{60}$ and $\mathrm{CH}_{4} @ \mathrm{C}_{60}$ were predicted to be almost the same. Calculated ${ }^{1} \mathrm{H} /{ }^{13} \mathrm{C}$ NMR shifts and spin-spin coupling constants were in very good agreement with experimental data. Lastly, selected points at the potential energy surface of the endohedral $\mathrm{He}_{2} @ \mathrm{C}_{60}$ trimer were calculated at the DLPNO$\operatorname{CCSD}(\mathrm{T})$ level of theory. In contrast to previous theoretical studies with DFT, MP2, SCS-MP2, and DFT-SAPT, where all these methods predicted the $\mathrm{He}_{2} @ \mathrm{C}_{60}$ to be thermodynamically unstable towards the loss of the noble gas atom, our calculations predicted the $\mathrm{He}_{2} @ \mathrm{C}_{60}$ to be stable, which is in agreement with experimental observations. Therefore, the case of the $\mathrm{He}_{2} @ \mathrm{C}_{60}$ trimer clearly indicated that the DLPNO$\operatorname{CCSD}(\mathrm{T})$ level of theory is indispensable in studies of weakly interacting systems and should be used whenever applicable.

\section{Conflicts of interest}

There are no conflicts to declare.

\section{Acknowledgements}

Computational resources of the Department of Materials and Environmental Chemistry, Stockholm University, are acknowledged.

\section{Notes and references}

1 H. W. Kroto, J. R. Heath, S. C. O'Brien, R. F. Curl and R. E. Smalley, Nature, 1985, 318, 162-163.

2 S. Iijima and T. Ichihashi, Nature, 1993, 363, 603-605.

3 D. S. Bethune, C. H. Kiang, M. S. de Vries, G. Gorman, R. Savoy, J. Vazquez and R. Beyers, Nature, 1993, 363, 605-607.

4 K. S. Novoselov, A. K. Geim, S. V. Morozov, D. Jiang, Y. Zhang, S. V. Dubonos, A. A. Grigorieva and A. A. Firsov, Science, 2004, 306, 666-669.
5 P. R. Buseck, S. J. Tsipursky and R. Hettich, Science, 1992, 257, 215-217.

6 J. B. Howard, J. T. McKinnon, Y. Makarovsky, A. L. Lafleur and M. E. Johnson, Nature, 1991, 352, 139-141.

7 F. R. di Brozolo, T. E. Bunch, R. H. Fleming and J. Macklin, Nature, 1994, 369, 37-40.

8 D. J. Kessler, J. Spacecr. Rockets, 1991, 28, 347-351.

9 L. Becker, R. J. Poreda and T. J. Bunch, Proc. Natl. Acad. Sci. U. S. A., 2000, 97, 2979-2983.

10 P. Ehrenfreund and B. H. Foing, Adv. Space Res., 1997, 19, 1033-1042.

11 M. A. Cordiner, H. Linnartz, N. L. J. Cox, J. Cami, F. Najarro, C. R. Proffitt, R. Lallement, P. Ehrenfreund, B. H. Foing, T. R. Gull, P. J. Sarre and S. B. Charnley, Astrophys. J., Lett., 2019, 875, 1-7.

12 M. Arndt, O. Nairz, J. Vos-Andreae, C. Keller, G. van der Zouw and A. Anton Zeilinger, Nature, 1999, 401, 680-682.

13 W. Krätschmer, D. Lamb, K. Fostiropoulos and D. R. Huffman, Nature, 1990, 347, 354-358.

14 D. S. Bethune, R. D. Johnson, J. R. Salem, M. S. de Vries and C. S. Yannoni, Nature, 1993, 366, 123-128.

15 J. R. Heath, S. C. O’Brien, Q. Zhang, Y. Liu, R. F. Curl, H. W. Kroto, F. K. Tittel and R. E. Smalley, J. Am. Chem. Soc., 1985, 107, 7779-7780.

16 T. Akasaka and S. Nagase, Endofullerenes: A New Family of Carbon Clusters, Kluwer Academic, Dodrecht, Netherlands, 2002.

17 T. Suetsuna, N. Dragoe, W. Harneit, A. Weidinger, H. Shimotani, S. Ito, H. Takagi and K. Kitazawa, Chem. Eur. J., 2002, 22, 5079-5083.

18 K. Komatsu, M. Murata and Y. Murata, Science, 2005, 307, 238-240.

19 K. Kurotobi and Y. Murata, Science, 2011, 333, 613-616.

20 S. Bloodworth, G. Sitinova, S. Alom, S. Vidal, G. R. Bacanu, S. J. Elliott, M. E. Light, J. M. Herniman, G. J. Langley, M. H. Levitt and R. J. Whitby, Angew. Chem., Int. Ed., 2019, 58, 5038-5043.

21 M. H. Levitt, Philos. Trans. R. Soc., A, 2013, 371, 20120429.

22 Z. Bačić, J. Chem. Phys., 2018, 149, 100901.

23 P. M. Felker and Z. Bačić, J. Chem. Phys., 2020, 152, 014108.

24 J. Cioslowski, J. Am. Chem. Soc., 1991, 113, 4139-4141.

25 J. Cioslowski, J. Am. Chem. Soc., 1994, 116, 3619-3620.

26 J. Cioslowski, Chem. Phys. Lett., 1994, 227, 361-364.

27 M. Bühl, W. Thiel, H. Jiao, P. von Ragué Schleyer, M. Saunders and F. A. L. Anet, J. Am. Chem. Soc., 1994, 116, 6005-6006.

28 M. Bühl, S. Patchkovskii and W. Thiel, Chem. Phys. Lett., 1997, 275, 14-18.

29 S. Patchkovskii and W. Thiel, J. Am. Chem. Soc., 1996, 118, 7164-7172.

30 R. B. Darzynkiewicz and G. E. Scuseria, J. Phys. Chem. A, 1997, 101, 7141-7144.

31 J. Autschbach and E. Zurek, J. Phys. Chem. A, 2003, 107, 4967-4972.

32 O. Charkin, N. Klimenko, D. Charkin and A. Mebel, Russ. J. Inorg. Chem., 2004, 49, 868-880. 
33 A. Rehaman, L. Gagliardi and P. Pyykkö, Int. J. Quantum Chem., 2006, 107, 1162-1169.

34 O. Shameema, C. N. Ramachandran and N. Sathyamurthy, J. Phys. Chem. A, 2006, 110, 2-4.

35 M. Straka and J. Vaara, J. Phys. Chem. A, 2006, 110, 12338-12341.

36 M. Straka, P. Lantto and J. Vaara, J. Phys. Chem. A, 2008, 112, 2658-2668.

37 K. E. Whitener, R. J. Cross, M. Saunders, I. Sho-ichi, S. Murata, N. Mizorogi and S. Nagase, J. Am. Chem. Soc., 2009, 131, 6338-6339.

38 S. Grimme, J. Comput. Chem., 2004, 25, 1463-1473.

39 S. Grimme, J. Comput. Chem., 2006, 27, 1787-1799.

40 S. Grimme, J. Antony, S. Ehrlich and H. Krieg, J. Chem. Phys., 2010, 132, 154104.

41 S. Grimme, S. Ehrlich and L. Goerigk, J. Comput. Chem., 2011, 32, 1456-1465.

42 E. Caldeweyher, S. Ehlert, A. Hansen, H. Neugebauer, S. Spicher, C. Bannwarth and S. Grimme, J. Chem. Phys., 2019, 150, 154122.

43 K. E. Riley, J. A. Platts, J. Řezáč, P. Hobza and J. G. Hill, J. Phys. Chem. A, 2012, 116, 4159-4169.

44 B. Jeziorski, R. Moszynski and K. Szalewicz, Chem. Rev., 1994, 94, 1887-1930.

45 A. J. Misquitta, R. Podeszwa, B. Jeziorski and K. Szalewicz, J. Chem. Phys., 2005, 123, 214103.

46 K. Szalewicz, Wiley Interdiscip. Rev.: Comput. Mol. Sci., 2012, 2, 254-272.

47 S. F. Boys and F. Bernardi, Mol. Phys., 1970, 19, 553-566.

48 T. Korona, A. Hesselmann and H. Dodziuk, J. Chem. Theory Comput., 2009, 5, 1585-1596.

49 A. Hesselmann and T. Korona, Phys. Chem. Chem. Phys., 2011, 13, 732-743.

50 P. Pyykkö, C. Wang, M. Straka and J. Vaara, Phys. Chem. Chem. Phys., 2007, 9, 2954-2958.

51 C. Wang, M. Straka and P. Pyykkö, Phys. Chem. Chem. Phys., 2010, 12, 6187-6203.

52 G. Bistoni, Wiley Interdiscip. Rev.: Comput. Mol. Sci., 2020, 10, 1-22.

53 R. J. Bartlett and M. Musiał, Rev. Mod. Phys., 2007, 79, 291-352.

54 C. Riplinger and F. Neese, J. Chem. Phys., 2013, 138, 034106.

55 C. Riplinger, B. Sandhoefer, A. Hansen and F. Neese, J. Chem. Phys., 2013, 139, 134101.

56 C. Riplinger, P. Pinski, E. Valeev and F. Neese, J. Chem. Phys., 2016, 144, 024109.

57 D. G. Liakos, M. Sparta, M. K. Kesharwani, J. M. L. Martin and F. Neese, J. Chem. Theory Comput., 2015, 11, 1525-1539.

58 D. Liakos, Y. Guo and F. Neese, J. Phys. Chem. A, 2020, 124, 90-100.

59 M. Sparta, M. Retegan, P. Pinski, C. Riplinger, U. Becker and F. Neese, J. Chem. Theory Comput., 2017, 13, 3198-3207.

60 F. Neese, M. Atanasov, G. Bistoni, D. Maganas and S. Ye, J. Am. Chem. Soc., 2019, 141, 2814-2824.
61 W. B. Schneider, G. Bistoni, M. Sparta, M. Saitow, C. Riplinger, A. A. Auer and F. Neese, J. Chem. Theory Comput., 2016, 12, 4778-4792.

62 A. Altun, F. Neese and G. Bistoni, J. Chem. Theory Comput., 2019, 15, 215-228.

63 F. Neese, Wiley Interdiscip. Rev.: Comput. Mol. Sci., 2011, 2, 73-78.

64 F. Neese, F. Wennmohs, U. Becker and C. Riplinger, J. Chem. Phys., 2020, 152, 224108.

65 F. Neese, F. Wennmohs, A. Hansen and U. Becker, Chem. Phys., 2009, 356, 98-109.

66 F. Weigend, Phys. Chem. Chem. Phys., 2006, 8, 1057-1065.

67 J. P. Perdew, K. Burke and M. Ernzerhof, Phys. Rev. Lett., 1996, 15, 3865.

68 Y. Zhang and W. Yang, Phys. Rev. Lett., 1998, 80, 890.

69 F. Jensen, J. Chem. Theory Comput., 2014, 10, 1074-1085.

70 L. Goerigk, A. Hansen, C. Bauer, S. Ehrlich, A. Najibi and S. Grimme, Phys. Chem. Chem. Phys., 2017, 19, 32184-32215.

71 Y. Guo, C. Riplinger, U. Becker, D. G. Liakos, Y. Minenkov and F. Neese, J. Chem. Phys., 2018, 148, 011101.

72 T. H. Dunning, J. Chem. Phys., 1989, 90, 1007-1023.

73 D. E. Woon and T. H. Dunning, J. Chem. Phys., 1993, 98, 1358-1371.

74 A. K. Wilson, D. E. Woon, K. A. Peterson and T. H. Dunning, J. Chem. Phys., 1999, 110, 7667.

75 F. Weigend, A. Köhn and C. Hättig, J. Chem. Phys., 2002, 116, 3175-3183.

76 F. Calbo, J. C. Sancho-García, E. Ortí and J. Aragó, J. Comput. Chem., 2017, 38, 1869-1878.

77 L. Gyevi-Nagy, M. A. Kállay and P. R. Nagy, J. Chem. Theory Comput., 2021, 17, 860-878.

78 T. Helgaker, W. Klopper, H. Koch and J. Noga, J. Chem. Phys., 1997, 106, 9639-9646.

79 V. Vasilyev, Comput. Theor. Chem., 2017, 1115, 1-3.

80 A. L. Ringer, M. S. Figgs, M. O. Sinnokrot and C. D. Sherill, J. Phys. Chem. A, 2006, 110, 10822-10828.

81 H. Hollenstein, R. R. Marquardt, M. Quack and M. A. Suhm, J. Chem. Phys., 1994, 101, 3588-3602.

82 K. Hedberg, L. Hedberg, D. S. Bethune, C. A. Brown, H. C. Dorn, R. D. Johnson and M. de Vries, Science, 1991, 254, 410-412.

83 J. Neugebauer, M. Reiher, C. Kind and B. A. Hess, J. Comput. Chem., 2002, 23, 895-910.

84 R. D. Amos, J. Chem. Soc., Faraday Trans., 1987, 83, 1595-1607. 85 D. S. Bethune, G. Meijer, W. C. Tang, H. J. Rosen, W. G. Golden, H. Seki, C. A. Brown and M. S. de Vries, Chem. Phys. Lett., 1991, 179, 181-186.

86 K. Yagi and D. Watanabe, Int. J. Quantum Chem., 2009, 109, 2080-2090.

87 B. Meier, S. Mamone, M. Concistré, J. Alonso-Valdesueiro, A. Krachmalnicoff, R. Whitby and M. Levitt, Nat. Commun., $2015,6,8112$.

88 A. Shugai, U. Nagel, Y. Murata, Y. Li, S. Mamone, A. Krachmalnicoff, S. Alom, R. J. Whitby, M. H. Levitt and T. Rõõm, J. Chem. Phys., 2021, 154, 124311. 
89 B. Ensing, F. Costanzo and P. L. Silvestrelli, J. Phys. Chem. A, 2012, 116, 12184-12188.

90 A. Krachmalnicoff, R. Bounds, S. Mamone, S. Alom, M. Concistrè, B. Meier, K. Kouřil, M. E. Light, M. R. Johnson, S. Rols, A. J. Horsewill, A. Shugai, U. Nagel, T. Rõõm, M. H. Carravetta, M. Levitt and R. J. Whitby, Nat. Chem., 2016, 8, 953-957.

91 P. Delaney and J. C. Greer, Appl. Phys. Lett., 2004, 84, 431-433.

92 A. V. Marenich, C. J. Cramer and D. G. Truhlar, Chem. Sci., 2013, 4, 2349-2356.

93 D. S. Sabirov, Fullerenes, Nanotubes, Carbon Nanostruct., 2020, 28, 71-77.

94 T. Yanai, D. P. Tew and N. C. Handy, Chem. Phys. Lett., 2004, 393, 51-57.

95 G. Skrzyński, K. Radula-Janik, T. Kupka and T. Pluta, J. Phys. Chem. A, 2019, 123, 9753-9762.

96 M. J. G. Peach, P. Benfield, T. Helgaker and D. J. Tozer, J. Chem. Phys., 2008, 128, 044118.

97 A. J. Sadlej, Collect. Czech. Chem. Commun., 1988, 53, 1995-2016.

98 A. J. Sadlej, Theor. Chim. Acta, 1992, 83, 351-366.

99 B. P. Pritchard, D. Altarawy, B. Didier, T. D. Gibson and T. L. Windus, J. Chem. Inf. Model., 2019, 59, 4814-4820.

100 U. Hohm and K. Kerl, Mol. Phys., 1990, 69, 803-817.

101 A. Ballard, K. Bonin and J. Lauderback, J. Chem. Phys., 2000, 113, 5732-5735.

102 C. Bannwarth and S. Grimme, Comput. Theor. Chem., 2014, 1040, 45-53.

103 S. Dai, L. M. Toth, G. D. Del Cul and D. H. Metcalf, J. Chem. Phys., 1994, 101, 4470.

104 D. K. Böhme, Philos. Trans. R. Soc., A, 2016, 374, 20150321.

105 A. V. Pogulay, R. R. Abzalimov, S. K. Nasibullaev, A. S. Lobach, T. Drewello and Y. V. Vasil'ev, Int. J. Mass Spectrom., 2004, 233, 165-172.
106 R. S. Ruoff, D. S. Tse, R. Malhotra and D. C. Lorents, J. Phys. Chem., 1993, 97, 3379-3383.

107 M. Saunders, H. A. Jiménez-Vázquez, R. J. Cross, S. Mroczkowski, D. I. Freedberg and F. A. L. Anet, Nature, 1994, 367, 256.

108 M. S. Syamala, R. J. Cross and M. Saunders, J. Am. Chem. Soc., 2002, 124, 6216-6219.

109 L. Martinez, R. Andrade, E. G. Birgin and J. M. Martinez, J. Comput. Chem., 2009, 30, 2157-2164.

110 N. F. Ramsey, Phys. Rev., 1950, 78, 699.

111 T. Helgaker, M. Jaszuński and K. Ruud, Chem. Rev., 1999, 99, 293-352.

112 K. Wolinski, J. F. Hilton and P. Pulay, J. Am. Chem. Soc., 1990, 112, 8251-8260.

113 C. Adamo and V. Barone, J. Chem. Phys., 1999, 110, 6158-6170.

114 F. Jensen, Theor. Chem. Acc., 2010, 126, 371-382.

115 F. Jensen, J. Chem. Theory Comput., 2015, 11, 132-138.

116 T. Kupka, M. Nieradka, M. Stachów, T. Pluta, P. Nowak, H. Kjær, J. Kongsted and J. Kaminsky, J. Phys. Chem. A, 2012, 116, 3728-3738.

117 P. Rzepka, Z. Bacsik, A. J. Pell, N. Hedin and A. Jaworski, J. Phys. Chem. C, 2019, 123, 21497-21503.

118 A. Antušek, K. Jackowski, M. Jaszuński, W. Makulski and M. Wilczek, Chem. Phys. Lett., 2005, 411, 111-116.

119 B. Bennett and W. T. Raynes, Mol. Phys., 1987, 61, 1423-1430.

120 T. Sternfeld, R. E. Hoffman, M. Saunders, R. J. Cross, M. S. Syamala and M. Rabinovitz, J. Am. Chem. Soc., 2002, 124, 8786-8787.

121 A. Krapp and G. Frenking, Chem. - Eur. J., 2007, 13, 8256-8270.

122 T. Y. Nikolaienko, E. S. Kryachko and G. A. Dolgonos, J. Comput. Chem., 2018, 39, 1090-1102.

123 A. Altun, F. Neese and G. Bistoni, J. Chem. Theory Comput., 2019, 15, 5894-5907. 